\title{
Estradiol Regulation of the Prelimbic Cortex and the Reinstatement of Cocaine Seeking in Female Rats
}

\author{
Elizabeth M. Doncheck,* Eden M. Anderson,* Chaz D. Konrath, Gage T. Liddiard, Margot C. DeBaker, \\ Luke A. Urbanik, ${ }^{-}$Matthew C. Hearing, and John R. Mantsch \\ Department of Biomedical Sciences, Marquette University, Milwaukee, Wisconsin 53201
}

Relapse susceptibility in women with substance use disorders (SUDs) has been linked to the estrogen, 17 $\beta$-estradiol (E2). Our previous findings in female rats suggest that the influence of E2 on cocaine seeking can be localized to the prelimbic prefrontal cortex (PrL-PFC). Here, we investigated the receptor mechanisms through which E2 regulates the reinstatement of extinguished cocaine seeking. Sexually mature female rats underwent intravenous cocaine self-administration $(0.5 \mathrm{mg} / \mathrm{inf} ; 14 \times 2 \mathrm{~h}$ daily) and extinction, and then were ovariectomized before reinstatement testing. E2 $(10 \mu \mathrm{g} / \mathrm{kg}$, i.p. $)$ alone did not reinstate cocaine seeking, but it potentiated reinstatement when combined with an otherwise subthreshold priming dose of cocaine. A similar effect was observed following intra-PrL-PFC microinfusions of E2 and by systemic or intra-PrL-PFC administration of the estrogen receptor (ER) $\beta$ agonist, DPN, but not agonists at ER $\alpha$ or the G-protein-coupled ER1 (GPER1). By contrast, E2potentiated reinstatement was prevented by intra-PrL-PFC microinfusions of the ER $\beta$ antagonist, MPP, or the GPER1 antagonist, G15, but not an ER $\alpha$ antagonist. Whole-cell recordings in PrL-PFC layer (L)5/6 pyramidal neurons revealed that E2 decreases the frequency, but not amplitude, of $\mathrm{GABA}_{\mathrm{A}}$-dependent miniature IPSCs (mIPSC). As was the case with E2-potentiated reinstatement, E2 reductions in mIPSC frequency were prevented by ER $\beta$ and GPER1, but not ER $\alpha$, antagonists and mimicked by ER $\beta$, but not GPER1, agonists. Altogether, the findings suggest that E2 activates ER $\beta$ and GPER1 in the PrLPFC to attenuate the GABA-mediated constraint of key outputs that mediate cocaine seeking.

Key words: cocaine; estrogen; prefrontal cortex; reinstatement relapse; sex differences

Significance Statement

Susceptibility to drug craving and relapse is heightened in women with cocaine use disorder and varies across the reproductive cycle, likely reflecting the influence of the estrogen, $17 \beta$-estradiol (E2). Here, we report that E2 promotes cocaine seeking in female rats through actions that involve the estrogen receptor (ER) $\beta$ and the G-protein-coupled ER1 (GPER1) in the prelimbic prefrontal cortex (PrL-PFC). These effects coincide with an ER $\beta$-dependent and GPER1-dependent suppression of GABA-mediated inhibition of pyramidal neurons that likely increases the excitability of prefrontal cortical output pathways involved in drug seeking. Determining how estrogens influence behavior via effects in the PFC is important for understanding both adaptive and maladaptive behaviors, including substance use, and has the potential to guide treatment.

Received Dec. 9, 2020; revised Mar. 10, 2021; accepted Apr. 8, 2021.

Author contributions: E.M.D., E.M.A., M.C.H., and J.R.M. designed research; E.M.D., C.D.K., G.T.L., M.C.D., L.A.U., M.C.H., and J.R.M. performed research; E.M.D., E.M.A., M.C.H., and J.R.M. analyzed data; J.R.M. and E. M.D. wrote the paper.

This work was supported by National Institute on Drug Abuse Grants DA 052169 (to J.R.M. and M.C.H.) and DA 038663 (to J.R.M.). We thank Dr. Jennifer Tuscher, Dr. Karyn Frick, Dr. Cecilia Hillard, and Dr. QingSong Liu for conceptual and technical advice and Jacob Mathy for his technical assistance.

J. R. Mantsch's present address: Department of Pharmacology and Toxicology, Medical College of Wisconsin, Milwaukee, Wisconsin 53226.

E. M. Doncheck's present address: Department of Neuroscience, Medical University of South Carolina, Charleston, South Carolina 29425.

*E.M.D. and E.M.A. contributed equally to this work.

The authors declare no competing financial interests.

Correspondence should be addressed to John R. Mantsch at jomantsch@mcw.edu.

https://doi.org/10.1523/JNEUROSCI.3086-20.2021

Copyright $\odot 2021$ the authors

\section{Introduction}

Although men are more likely to use cocaine (Substance Abuse and Mental Health Services Administration, 2020), women progress more rapidly to uncontrolled cocaine use (Griffin et al., 1989; Kosten et al., 1993; Haas and Peters, 2000), report greater levels of drug craving (Robbins et al., 1999; Elman et al., 2001; Kennedy et al., 2013), and are more susceptible to relapse (Gallop et al., 2007). Sex differences are likely attributable, in part, to gonadal hormones, as drug craving and use can vary across the menstrual cycle (Sofuoglu et al., 1999; Terner and de Wit, 2006). Understanding the neurobiological processes that underlie these sex differences is critical for the development of effective interventions for substance use disorders (SUDs; Becker and Chartoff, 2019).

Under conditions where there are no apparent sex differences in cocaine self-administration or extinction, female rats are more 
sensitive to cocaine-primed reinstatement (Lynch and Carroll, 2000; Kerstetter et al., 2008; Doncheck et al., 2020). This elevated sensitivity likely reflects the influence of gonadal hormones, as it varies across the estrous cycle (Doncheck et al., 2018). In contrast to reports that sensitivity to cocaine-primed reinstatement is increased during estrus (Kippin et al., 2005; Feltenstein and See, 2007), we find that, similar to stress-induced and cue-induced reinstatement (Feltenstein et al., 2011), low-dose cocaine-primed reinstatement is most pronounced in proestrus (Doncheck et al., 2018), when circulating $17 \beta$-estradiol (E2) is elevated. Thus, we hypothesize that reinstatement is augmented by peak physiological elevations in E2 in female rats. In support, E2 administration to ovariectomized females at a dose that mimics proestrus levels potentiates cocaine-primed reinstatement (Doncheck et al., 2018). E2 alone does not increase cocaine seeking, but it does promote reinstatement in response to a low $(1.25 \mathrm{mg} / \mathrm{kg}$, i.p.) cocaine priming dose.

The prefrontal cortex (PFC) mediates relapse and is a likely site for hormone-dependent modulation of this behavior. In humans, cocaine-associated cues increase metabolic activity in subregions of the PFC in both sexes (Maas et al., 1998; Bonson et al., 2002); however, this activity is greater in women (Kilts et al., 2004). Studies in rodents support a specific role for the prelimbic (PrL)-PFC in relapse, as cocaine administration directly into this subregion triggers (Park et al., 2002) while pharmacological or optogenetic inhibition prevents reinstatement (Capriles et al., 2003; McFarland et al., 2003; Stefanik et al., 2013). Further, E2-enhanced reinstatement in female rats corresponds to heightened PrL-PFC c-fos reactivity (Zhou et al., 2014). We previously demonstrated that PrL-PFC E2 microinfusions can potentiate cocaine seeking in ovariectomized females (Doncheck et al., 2018). However, the mechanisms through which E2 regulates PrLPFC function and cocaine seeking are unclear.

E2 produces genomic and rapid non-genomic effects via $\mathrm{ER} \alpha$ and $\operatorname{ER} \beta$ receptors and signals through a G-protein-coupled receptor, GPER1 (GPR30), all of which are expressed in the rat PrL-PFC (Almey et al., 2014). Systemic administration of ER $\beta$, but not $\mathrm{ER} \alpha$, agonists mimics $\mathrm{E} 2$ effects on reinstatement (Larson and Carroll, 2007). While GPER1 contributions to E2 effects on reinstatement have not been reported, recent studies highlight a role in modulating the acquisition of cocaine self-administration (Sun et al., 2020). In the PrL-PFC, ER $\alpha$, $\operatorname{ER} \beta$, and GPER1 are primarily localized to axons/terminals, although postsynaptic and astrocytic expression has been described (Kritzer and Creutz, 2008; Almey et al., 2014; Crimins et al., 2017). ER $\beta$ is predominantly, albeit not exclusively, localized to fast-spiking parvalbumin (PV)expressing interneurons in the neocortex (Blurton-Jones et al., 2004). In cortical neurons, E2 has been shown to attenuate $\mathrm{GABA}_{\mathrm{A}}$ receptor $\left(\mathrm{GABA}_{\mathrm{A}} \mathrm{R}\right)$-dependent inhibition (Mukherjee et al., 2017). Thus, E2 may promote reinstatement by dampening GABA-mediated inhibition of PrL-PFC projection neurons that mediate drug seeking. However, the effects of $\mathrm{E} 2$ on synaptic transmission are complex, as it has been shown to augment excitatory transmission in the hippocampus (Wong and Moss, 1992; Gu and Moss, 1996; Smejkalova and Woolley, 2010) and striatum (Krentzel et al., 2019). Here, we examine the PrL-PFC receptor mechanisms through which $\mathrm{E} 2$ regulates synaptic activity and potentiates cocaine-primed reinstatement following self-administration and extinction in ovariectomized female rats.

\section{Materials and Methods}

\section{Subjects}

Sexually mature female Sprague Dawley rats (90-d-old/250 g minimum at study onset) were obtained from Envigo (Indianapolis) and singlehoused under a reversed 12/12 h light/dark cycle (lights off at 7 A.M.) with ad libitum access to standard rat chow and water. Experiments were performed in the dark phase and in accordance with the National Institutes of Health Guide for the Care and Use of Laboratory Animals, Ed 8. All experiments were approved by the Marquette University Institutional Animal Care and Use Committee.

\section{Drugs}

Cocaine $\mathrm{HCl}$ was obtained from RTI International via the NIDA Drug Supply Program. Water-soluble 2-hydroxypropyl- $\beta$-cyclodextrin (HBC; \#H107) and HBC-encapsulated E2 (\#E4389; $46.7 \mathrm{mg}$ E2 per gram of total powder) were obtained from Sigma, PHTPP (2phenyl-3-(4-hydroxyphenyl)-5,7-bis(trifluoromethyl)-pyrazolo[1,5a]pyrimidine, 4-[2-phenyl-5,7-bis(trifluoromethyl)pyrazolo[1,5-a]pyrimidin-3-yl]pheno; \#2662), DPN (diarylpropionitrile; \#1494), MPP (methyl-piperidino-pyrazole; \#1991), and PPT (2,8-bis(diphenylphosphoryl)dibenzo[b,d]thiophene; \#1426) from Tocris, and G15 (\#41004003) and G-1 (\#41004001) from Sandia Biotech.

\section{Cocaine self-administration, extinction, and reinstatement}

For experiments involving self-administration, animals were surgically implanted with venous catheters, and, in some instances, intracranial guide cannulae under isoflurane anesthesia, as previously described (Doncheck et al., 2018, 2020). Operant conditioning chambers, fitted with retractable levers and cue lights, housed in sound-attenuating compartments were used for self-administration (Med Associates). Training was conducted as previously described (Doncheck et al., 2020). Rats were initially trained to press an active lever under a fixed ratio (FR)1 schedule of sucrose pellet reinforcement, with the associated cue light indicating reward availability. Sucrose pellet training sessions, lasted $2 \mathrm{~h}$ or until 100 pellets were acquired. Sucrose pellet self-administration was typically acquired in a single session and was acquired by all rats within three sessions. Rats were not food-restricted during sucrose pellet training. As soon as a rat self-administered 100 pellets in a session, it was transitioned to cocaine $(0.5 \mathrm{mg} / \mathrm{kg} / 0.2 \mathrm{ml}$ infusion), which was initially available under a FR1 schedule during daily 2-h sessions. Infusions were delivered over the course of $5 \mathrm{~s}$, followed by a 10-s time-out period during which lever pressing was not reinforced and the cue light above the active lever switched off. Responding on a non-reinforced, inactive lever was also recorded. Once rats received 20 infusions under the FR1 schedule, the response requirements were increased to FR2, and once 20 infusions were received under the FR2 schedule, the requirements were increased to FR4. When stable responding was observed under the FR4 schedule ( $>20$ infusions for three consecutive sessions) was observed, self-administration continued for $14 \mathrm{~d}$, after which the cocaine syringe was replaced with saline and animals underwent extinction training.

\section{Extinction}

Sessions were identical to self-administration conditions except that responding on the previously active lever resulted in saline infusions instead of cocaine. Once responding dropped below the extinction criterion ( $<15$ total lever presses/2-h session for two of three last consecutive sessions), rats underwent surgical ovariectomy (see below).

\section{Reinstatement testing}

Following a one-week recovery from surgical ovariectomy, rats underwent additional extinction training until responding once again dropped below criterion followed by a test for reinstatement. Test sessions were 2 $\mathrm{h}$ in duration and otherwise identical to extinction sessions. Rats were tested multiple times for reinstatement using a counterbalanced design and extinction criterion re-established between tests.

\section{Surgical ovariectomy}

All rats underwent surgical ovariectomy. Bilateral surgical ovariectomy was conducted using a dorsal approach as previously reported 
(Doncheck et al., 2018) under isoflurane anesthesia. Successful ovariectomy was verified one week later by microscopy determination of estrous cycle using vaginal tissue samples obtained through distilled water lavage. Following recovery, rats were designated for reinstatement testing or electrophysical recording.

\section{Electrophysiology}

Acutely isolated brain slices containing the PrL-PFC were acquired from rats with no history of cocaine self-administration (postnatal day $165 \pm 6) \sim 31 \pm 5$ (mean \pm SE) days following ovariectomy. These rats were lightly anesthetized using isoflurane and decapitated. Coronal brain slices were made at $300 \mu \mathrm{m}$ with a Leica VT1000S vibratome in oxygenated $\left(95 \% \mathrm{O}_{2}: 5 \% \mathrm{CO}_{2}\right)$ ice-cold (slush) sucrose-based solution containing $229 \mathrm{~mm}$ sucrose, $1.9 \mathrm{~mm} \mathrm{KCl}, 1.2 \mathrm{~mm} \mathrm{NaH}_{2} \mathrm{PO}_{4}, 33 \mathrm{~mm} \mathrm{NaHCO}_{3}, 10$ mu glucose, $0.4 \mathrm{~mm}$ ascorbic acid, $6 \mathrm{~mm} \mathrm{MgCl}_{2}$, and $0.5 \mathrm{~mm} \mathrm{CaCl}_{2}$. Slices were allowed to recover in a solution containing $119 \mathrm{~mm} \mathrm{NaCl}, 2.5$ $\mathrm{mm} \mathrm{KCl}, 1 \mathrm{~mm} \mathrm{NaH} \mathrm{PO}_{4}, 26.2 \mathrm{~mm} \mathrm{NaHCO} 3,11 \mathrm{~mm}$ glucose, $0.4 \mathrm{~mm}$ ascorbic acid, $4 \mathrm{~mm} \mathrm{MgCl}_{2}$, and $1 \mathrm{mM} \mathrm{CaCl}_{2}$ for $10 \mathrm{~min}$ at $31^{\circ} \mathrm{C}$ then allowed to slowly cool to room temperature for a minimum of $35 \mathrm{~min}$. Following incubation, slices were transferred to a recording chamber and imaged under an upright microscope (Q Imaging Rolera and Olympus BX51WI). Slices were maintained at $31 \pm 2{ }^{\circ} \mathrm{C}$ using an inline temperature controller (Warner Instrument Corporation TC-344B) and perfused with oxygenated recording aCSF $(125 \mathrm{~mm} \mathrm{NaCl}, 2.5 \mathrm{~mm} \mathrm{KCl}$, $25 \mathrm{~mm} \mathrm{NaHCO}_{3}, 10 \mathrm{~mm}$ glucose, $0.4 \mathrm{~mm}$ ascorbic acid, $1.3 \mathrm{~mm} \mathrm{MgCl}$, and $2 \mathrm{mM} \mathrm{CaCl}_{2}$ ) at a constant rate of $1.5-2.5 \mathrm{ml} / \mathrm{min}$. Data acquisition was performed using an integrated patch amplifier (IPA; Sutter Instrument) and analysis software Igor Pro 7 (WaveMetrics). Pyramidal neurons were identified as previously described (Anderson et al., 2019; Hearing et al., 2013). Miniature EPSCs (i.e., AMPAR-mediated mEPSCs) and miniature IPSCs (GABA ${ }_{A}$ R-mediated mIPSC) were recorded from the same neurons in the presence of the $\mathrm{Na}^{+}$channel blocker lidocaine $(0.7 \mathrm{~mm})$ while voltage-clamped at -70 or $0 \mathrm{mV}$, respectively. Borosilicate electrodes (2.5-4.5 M 2 ) were filled with 120 mm CsMeSO ${ }_{4}, 15$ mm CsCl, 10 mм TEA-Cl, 8 mm NaCl, 10 mм HEPES, 5 mm EGTA, $0.1 \mathrm{~mm}$ spermine, $5 \mathrm{~mm}$ QX-314, $4 \mathrm{~mm}$ ATP-Mg, and 0.3 $\mathrm{mM}$ GTP-Na (pH 7.4). Only recordings with a series resistance of 10-40 $\mathrm{M} \Omega$ that were collected within $5 \mathrm{~h}$ of slicing were used in data analysis. Signals were filtered at $2 \mathrm{kHz}$ and recordings were sampled at $20 \mathrm{kHz}$.

Water-soluble E2 was supplied encapsulated in HBC. Stock solution of encapsulated E2 (934.24 $\mu \mathrm{M})$ was freshly dissolved in aCSF containing $10 \%$ dimethylsulfoxide (DMSO) and further diluted into aCSF for a final concentration of $0.934 \mu \mathrm{M}$ encapsulated $\mathrm{E} 2$ in $0.01 \% \mathrm{DMSO}$ in accord with past work (Wong and Moss, 1992). The final HBC concentration was $3.721 \mu \mathrm{M}$, well below that demonstrated to promote the activation of $\mathrm{GABA}_{\mathrm{A}}$ Rs (Pytel et al., 2006). For all recordings, a 5-min equilibration period was given after achieving whole-cell status. Before drug (E2, agonists, antagonists), baselines were taken following 5- to 10-min application of the same concentration of HBC and DMSO in aCSF to ensure changes in synaptic activity are attributed to drug effects. A subset of recordings was performed where baseline was recorded in aCSF and following 10 min of $\mathrm{HBC}$ to ensure that $\mathrm{HBC}$ alone did not alter synaptic transmission and that extending the time postbaseline did not alter the effects of E2 as studies with antagonist application required an additional $10 \mathrm{~min}$ of drug application. ER antagonists were applied for $10 \mathrm{~min}$ following 5-min HBC baseline and in conjunction with subsequent E2 application. ER agonists were applied for $10 \mathrm{~min}$ following baseline recordings. All antagonists and agonists were prepared in 100\% DMSO with the latter diluted to a final concentration in the aCSF bath of $0.01 \%$ $(\mathrm{v} / \mathrm{v})$.

\section{Experiment \# 1}

Potentiation of cocaine-primed reinstatement by systemic administration of E2 and ER agonists

We previously found that proestrus-level E2 potentiates cocaine-primed reinstatement (Doncheck et al., 2018). To re-establish this effect, rats $(n=12)$ received iv catheters and underwent cocaine self-administration, extinction, and surgical ovariectomy. After postoperative recovery, extinction was re-established, and rats were tested for the ability of E2
(10 $\mu \mathrm{g} / \mathrm{kg}$, i.p.) or vehicle (containing HBC; $208.4 \mu \mathrm{g} / \mathrm{kg}$, i.p.) to potentiate reinstatement in response to a $1.25 \mathrm{mg} / \mathrm{kg}$ priming dose of cocaine. The E2 dose was selected based on our previous work demonstrating that it mimics circulating proestrus levels (McHenry et al., 2017; Doncheck et al., 2018). A dose of $1.25 \mathrm{mg} / \mathrm{kg}$ cocaine was chosen for all reinstatement tests as we have previously shown it to be subthreshold for cocaine-primed reinstatement in female rats following ovariectomy (Doncheck et al., 2018, 2020). For these studies (data in Fig. 1B), each rat was tested under each of the following conditions in counter-balanced sequence: vehicle/saline, E2/saline, vehicle/cocaine, and E2/cocaine. E2 or vehicle was systemically administered (intraperitoneally) $60 \mathrm{~min}$ before administration of cocaine or saline, after which rats were immediately placed into the operant chambers for reinstatement testing.

In a separate group of rats, we used an agonist approach to determine whether $\mathrm{ER} \alpha, \mathrm{ER} \beta$, or GPER1 activation is sufficient to potentiate cocaine-primed reinstatement (Fig. $1 C-E$ ). For reinstatement, rats received a subcutaneous injection of vehicle or an $\mathrm{ER} \alpha$ (PPT, $1.0 \mathrm{mg} / \mathrm{kg}$; Lund et al., 2005; Larson and Carroll, 2007; Kastenberger et al., 2012), ER $\beta$ (DPN, $1 \mathrm{mg} / \mathrm{kg}$; Lund et al., 2005; Larson and Carroll, 2007; Kastenberger et al., 2012), or GPER1 (G-1, 1 mg/kg; Kastenberger et al., 2012) agonist, $30 \mathrm{~min}$ before a cocaine injection, as above. Rats only received treatment with one agonist (PPT, $n=5$; DPN, $n=7$; G-1, $n=6$ ), and each rat was tested under the following conditions in counter-balanced sequence: vehicle/saline, agonist/saline, vehicle/cocaine, agonist/ cocaine.

\section{Experiment \#2}

Effects of E2 in the PrL-PFC on reinstatement of cocaine seeking and synaptic transmission

We previously localized the effects of E2 on cocaine-primed reinstatement to the PrL-PFC (Doncheck et al., 2018). To re-establish this effect, rats $(n=10)$ received bilateral cannulae targeting the PrL-PFC at the time of catheter implantation and subsequently underwent self-administration, extinction, and ovariectomy. For reinstatement testing, E2 $(5 \mu \mathrm{g}$, encapsulated in $\mathrm{HBC})$ or vehicle $(104.2 \mu \mathrm{g} \mathrm{HBC} /$ side $)$ was microinfused bilaterally into the PrL-PFC $(0.3 \mu \mathrm{l} /$ side over $60 \mathrm{~s}) 15 \mathrm{~min}$ before cocaine or saline injections (intraperitoneal) followed immediately by reinstatement testing (Fig. $2 A-C$ ). Each rat was tested under the following conditions, in counter-balanced sequence: PrL vehicle/saline, PrL vehicle/ cocaine, PrL E2/saline, PrL E2/cocaine. Rats were re-extinguished to criterion between tests, and animals with anatomic misses were excluded from the study $(n=2)$.

In a separate cohort of ovariectomized females with no history of cocaine, whole-cell voltage clamp recordings were conducted in PrL-PFC layer (L)5/6 pyramidal neurons. Following an initial period to allow cells to equilibrate to the internal solution, vehicle (HBC in $0.01 \%$ DMSO) was bath applied for $5 \mathrm{~min}$, after which baseline measures of AMPARmediated mEPSCs and/or GABA $\mathrm{A}$-mediated mIPSCs were taken, followed by a second assessment $10 \mathrm{~min}$ after co-application of $\mathrm{HBC}$ and E2 $(1 \mu \mathrm{M})$.

\section{Experiment \#3}

Contribution of ERs to PrL-E2 effects on reinstatement and inhibitory synaptic transmission

Antagonists for the ER $\alpha$ (MPP, $16 \mu \mathrm{g} /$ side; Domínguez-Ordóñez et al., 2016), ER $\beta$ (PHTPP, 800 ng; Pereira et al., 2014), or GPER1 (G-15, $7.5 \mathrm{ng}$; Kim et al., 2016) receptors were infused into the PrL-PFC to determine the contribution of ER subtypes to E2-potentiated reinstatement. Antagonists were bilaterally infused $(0.3 \mu \mathrm{l} /$ side over $60 \mathrm{~s}) 15 \mathrm{~min}$ before systemic injection of $\mathrm{E} 2$ or vehicle. One hour later, rats were given a systemic injection of cocaine or saline (intraperitoneal) followed by a 2-h reinstatement test. A separate group of rats was used for each antagonist (MPP, $n=7$; PHTPP, $n=10$; G-15, $n=8$; Fig. $3 B-E$ ). Within each group a counterbalanced approach was used under the following conditions: PrL vehicle + E2/saline (intraperitoneal); PrL vehicle + vehicle/ cocaine; $\operatorname{PrL}$ vehicle + vehicle/saline; $\operatorname{PrL}$ vehicle + E2/cocaine; $\operatorname{PrL}$ antagonist $+\mathrm{E} 2 /$ cocaine. As above, animals were re-extinguished to criterion between tests. Animals with anatomic misses were excluded (MPP, $n=0$; PHTPP, $n=2$; G-15, $n=1$ ). 
To determine the mechanism by which E2 mediates its cellular effects, mIPSCs were examined in the presence of aCSF or antagonists for $\mathrm{ER} \alpha, \mathrm{ER} \beta$, and GPER1 (Fig. $3 F-J$ ). Following a 5-min application of HBC, MPP ( $3 \mu \mathrm{M}$; Wang et al., 2016), PHTPP (3 $\mu \mathrm{M}$; Wang et al., 2016; Clemens et al., 2019), or G15 (500 nM; Wang et al., 2016) were applied for $10 \mathrm{~min}$ followed by a subsequent 10 -min application of E2 $(1 \mu \mathrm{M})$ with antagonist. mIPSCs were recorded following each 10-min drug application. As studies with antagonist application required an additional $10 \mathrm{~min}$ of drug application following the baseline recording, a subset of experiments involved application of $\mathrm{HBC}$ for $10 \mathrm{~min}$ to ensure extending the time postbaseline did not alter the effects of E2 on mIPSCs.

\section{Experiment \#4}

Effects of intra-PrL ER agonist administration on reinstatement of cocaine seeking

To determine whether PrL-PFC ER $\beta$ or GPER1 activation is sufficient to potentiate reinstatement, rats received bilateral PrL-PFC infusions $(0.3 \mu \mathrm{l} / \mathrm{side}$ over $60 \mathrm{~s})$ of DPN (10 or $100 \mathrm{pg}$, Boulware et al., 2013) or G-1 (4 or 40 ng; Kim et al., 2016), 15 min before administration of cocaine or saline (intraperitoneal) and a subsequent 2-h reinstatement test. Separate groups of rats were used for each agonist (DPN $n=8$; G-1 $n=8$; Fig. $4 B, C$ ). Within each group, a counterbalanced approach was used under the following conditions: PrL vehicle/saline; $\operatorname{PrL}$ vehicle/cocaine; PrL agonist/saline, PrL agonist/ cocaine. Rats were re-extinguished to criterion between tests and animals with anatomic misses were excluded from each study (DPN, $n=0$; G$1, n=1)$.

To determine whether activation of either $\mathrm{ER} \beta$ or GPER1 receptors is sufficient to reduce PrL-PFC inhibitory synaptic transmission, we measured agonist-induced effects on mIPSCs (Fig. 4F,G). mIPSC baseline was obtained 10 min after HBC application as well as following a 10-min application of DPN (100 nM, Huang and Woolley, 2012) or G-1 (100 nM; Oberlander and Woolley, 2016). An additional assessment was taken following a subsequent 10-min application of both agonist and E2 in combination to determine whether E2 had further effects on inhibitory synaptic transmission.

Experimental design and statistical analysis All sample sizes were determined using power analyses with parameters based on prior results. Reinstatement of cocaine-seeking behavior was assessed in experiments 1-4. Cocaine (lever presses/2-h session) in these experiments was analyzed within-subjects across treatment conditions and between corresponding extinction and reinstatement sessions using two-way repeated measures ANOVA. When applicable, Bonferroni-corrected $t$ tests comparisons were performed using SPSS Statistic Software. MiniAnalysis (Synaptosoft) was used to analyze slice electrophysiology data collected in experiments 2-4. Datasets were compared with paired Student's $t$ test or a one-way repeated measures ANOVA with significant findings further explored using Tukey's post hoc comparisons. Recording obtained with an amplitude or frequency \pm 2 SD from the

B
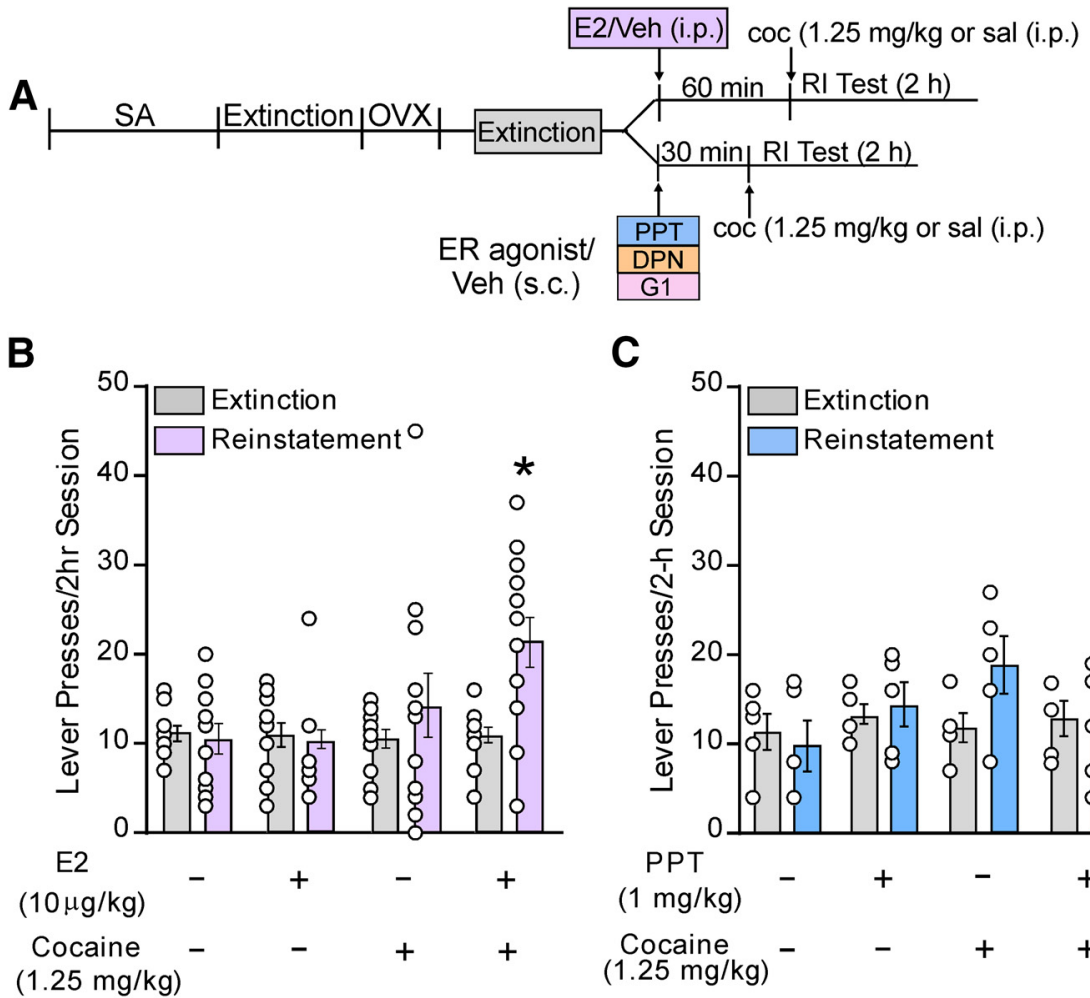

C
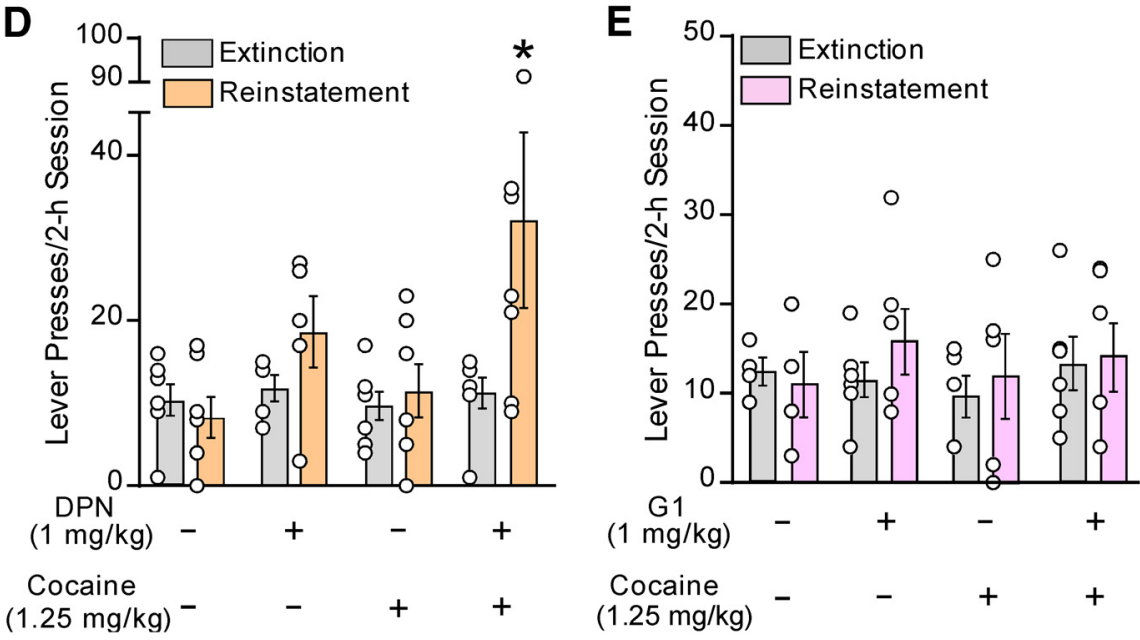

Figure 1. Systemic administration of estradiol (E2) or an ER $\beta$ agonist, but not an ER $\alpha$ or GPER1 agonist, potentiates cocaine-primed reinstatement following self-administration, extinction, and ovariectomy (OVX). $A$, Schematic outlining the experimental timeline of self-administration (SA), extinction, OVX, and reinstatement testing (RI) for the effects of systemic administration of E2, vehicle (Veh), or ER agonists before a cocaine (coc; $1.25 \mathrm{mg} / \mathrm{kg}$ ) or saline (sal) priming injection. Separate cohorts were used for E2 and agonist administration but underwent multiple testing conditions using a counter balanced design. Systemic effects of $(\boldsymbol{B})$ E2, $(\boldsymbol{C})$ the ER $\alpha$ agonist PPT, (D) the ER $\beta$ agonist DPN, and $(\boldsymbol{E})$ the GPER1 agonist G1 on active lever presses during a 2-h reinstatement test. In each case, cocaine, E2, PPT, DPN, or G1 alone did not alter reinstatement. The combinations of cocaine and E2 and cocaine and DPN, but not cocaine, E2, PPT, DPN, or G1 alone increased responding compared with extinction. Active lever pressing was also higher in E2/cocaine and DPN/cocaine groups compared with all other testing conditions within their respective groups; $* p<0.05$ versus extinction.

mean was excluded from analyses. Electrophysiology sample sizes are denoted as $n$ for the number of recordings/cells and $N$ for the number of rats. In all cases, results were considered to be significant at $p<0.05$.

\section{Results}

Cocaine self-administration and extinction

Cocaine self-administration (infusions/session for each group) and extinction (responding and number of days to meet criteria) 

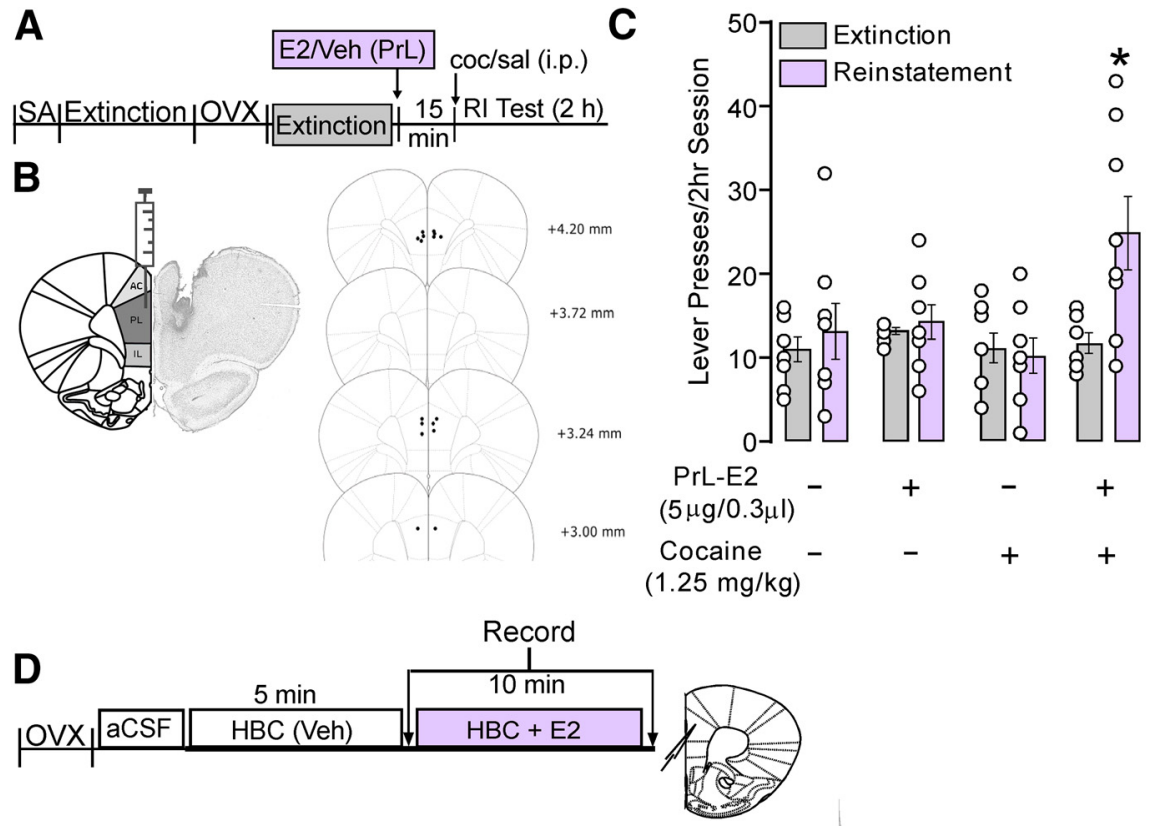

E

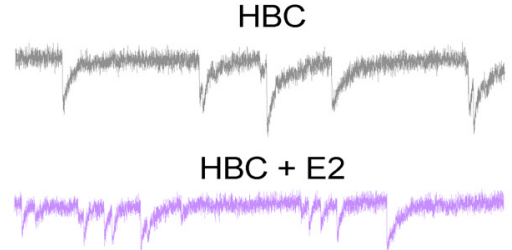

G

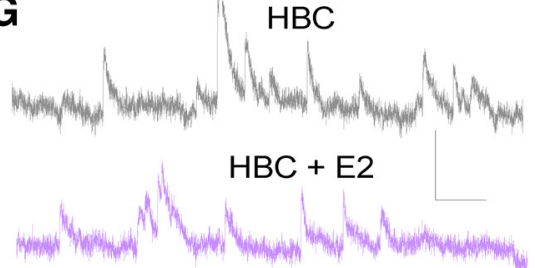

$\mathbf{F}$

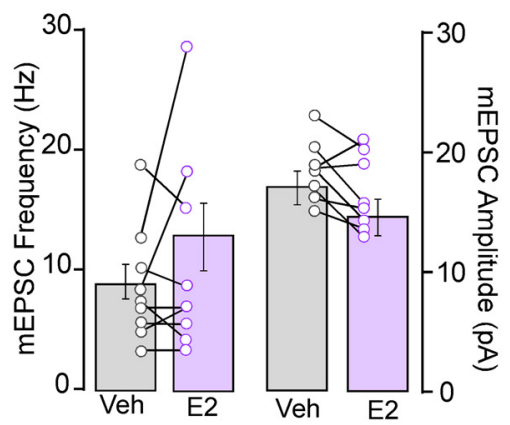

H

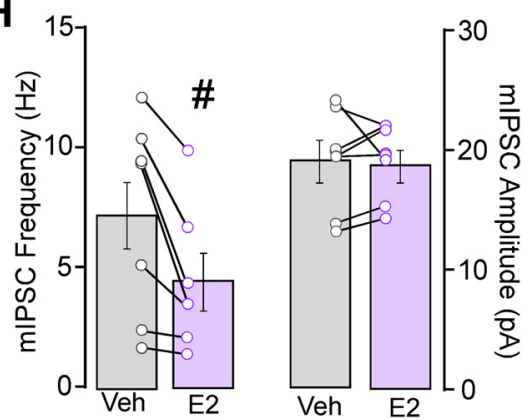

Figure 2. PrL-PFC E2 potentiates cocaine-primed reinstatement and attenuates inhibitory synaptic transmission in PrL-PFC pyramidal neurons. $\boldsymbol{A}$, Schematic depicting the experimental timeline of behavior studies involving SA, extinction, OVX, and intra-PrL infusions of E2 or Veh before priming injections and subsequent reinstatement testing. $\boldsymbol{B}$, Schematics depicting the E2 microinfusion strategy and PrL-PFC cannula placements. $\boldsymbol{C}$, Comparison of mean active lever presses during reinstatement testing shows that bilateral microinfusions of E2 elevated responding compared with extinction and that this responding was greater compared with all other testing conditions. $\boldsymbol{D}$, Experimental timeline of ex vivo whole-cell recordings in PrL-PFC L5/6 pyramidal neurons from OXV rats with no history of cocaine. Data were collected at time points denoted by arrows. $\boldsymbol{E}$, Representative traces for $\mathrm{mEPSC}$ recorded at $-70 \mathrm{mV}$ and $(\boldsymbol{G}) \mathrm{mIPSCS}$ recorded at $0 \mathrm{mV}$ following bath application of $\mathrm{HBC}$ (top, gray) and E2 (bottom, purple; scale: $20 \mathrm{pA} / 0.10 \mathrm{~s}$ ). $\boldsymbol{F}$, Within cell comparison shows that application of E2 failed to alter mEPSC frequency (left) and amplitude (right) compared with vehicle. $\boldsymbol{H}$, Within cell comparisons show that application of E2 significantly reduced mIPSC frequency but not amplitude compared with vehicle. $* p<0.05$ versus extinction, \#p $<0.05$, E2 versus $H B C$.

data for experiments in which reinstatement was tested are included in Table 1.

Experiment \#1: E2-potentiation of cocaine-primed reinstatement is mimicked by activation of ER $\beta$ and GPER 1 In agreement with our past findings (Doncheck et al., 2018), we found that reproducing proestrus-level E2 concentrations in the blood potentiated cocaine-primed reinstatement ( $n=16$; Fig.
1B). A $2 \times 4$ within-subject ANOVA with reinstatement (extinction vs reinstatement) $\times$ treatment condition (vehicle/saline, vehicle/cocaine, E2/saline, E2/ cocaine) revealed significant main effects of reinstatement $\left(F_{(1,44)}=6.39, p=0.02\right)$ and treatment $\left(F_{(3,44)}=3.03, p=0.04\right)$ and a significant interaction between treatment and reinstatement $\left(F_{(3,44)}=\right.$ 4.59, $p<0.01)$. Post hoc comparisons showed that the combination of E2 and cocaine administration $(p<0.05$ vs extinction) but not vehicle/saline, vehicle/cocaine, or E2/saline increased responding above extinction levels. Moreover, responding during the reinstatement session was significantly increased following E2/cocaine in combination compared with that following E2/ saline or vehicle/cocaine $(p<0.05)$.

The ability of E2 to potentiate reinstatement was reproduced by administration of the $\operatorname{ER} \beta$ agonist, DPN (Fig. $1 C)$, but not the $\mathrm{ER} \alpha$ agonist, PPT (Fig. 1D), or the GPER1 agonist, G1 (Fig. $1 E$ ). Separate $2 \times 4$ within-subject reinstatement $\times$ treatment (vehicle/saline, vehicle/cocaine, agonist/saline, agonist/cocaine) ANOVAs were used to assess the effects of each agonist on reinstatement of cocaine seeking. For the DPN and G1 cohorts, no main effects of reinstatement (DPN: $F_{(1,16)}=$ 1.04, $p=0.32 ; \mathrm{G}-1: F_{(1,17)}=0.46$, $p=0.57)$ or treatment (DPN: $F_{(3,16)}=$ 2.22, $p=0.46 ; \quad \mathrm{G}-1: F_{(3,17)}=0.83$, $p=0.29)$ or reinstatement $\times$ treatment interactions $\left(\mathrm{DPN}: F_{(3,16)}=2.24\right.$, $\left.p=0.12 ; \mathrm{G}-1: F_{(3,17)}=0.76, p=0.39\right)$ were found. Examination of effects in the DPN cohort using a two-way repeated measures ANOVA revealed a main effect of reinstatement $\left(F_{(1,22)}=\right.$ 5.26, $p=0.03$ ) and a significant interaction between reinstatement and treatment $\left(F_{(3,22)}=3.10, p=0.05\right)$, but no overall effect of treatment $\left(F_{(3,22)}=\right.$ 1.50, $p=0.08$ ). Post hoc testing showed that, similar to E2, the combination of DPN and cocaine $(p<0.05)$ but not vehicle/saline, vehicle/cocaine, or DPN/saline increased responding above extinction levels. Additionally, responding during the reinstatement session was significantly increased following the DPN/cocaine combination compared with that following vehicle/cocaine $(p<0.05)$, albeit not DPN/saline.

\section{Experiment \#2: PrL-PFC E2 potentiates cocaine-primed reinstatement and reduces $G A B A_{A} R$-mediated synaptic transmission}

To confirm our previous findings that the PrL-PFC is a site of action by which E2 potentiates cocaine seeking (Doncheck et al., 

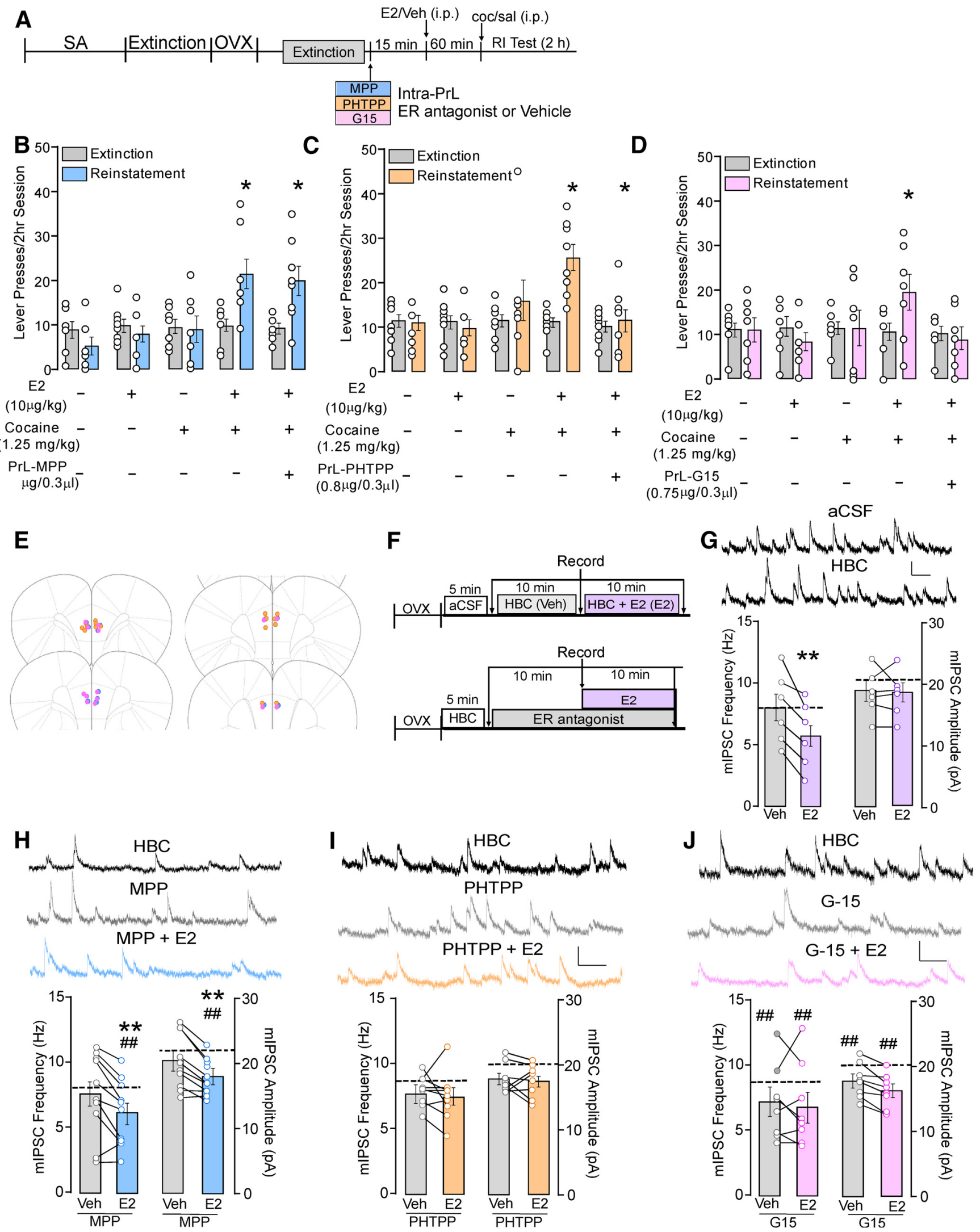

aCSF
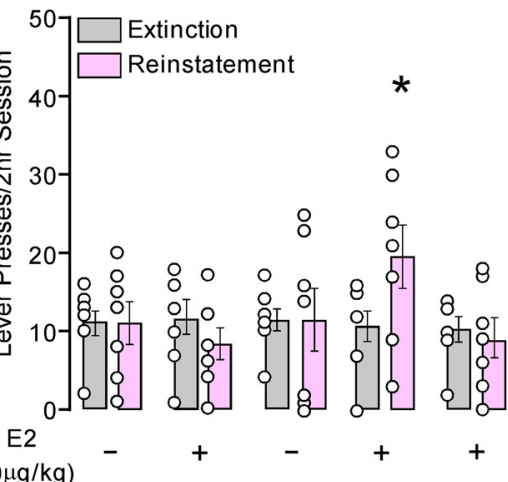

- $\quad+\quad+\quad+$

PrL-G15

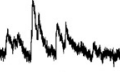

$\mathrm{HBC}$
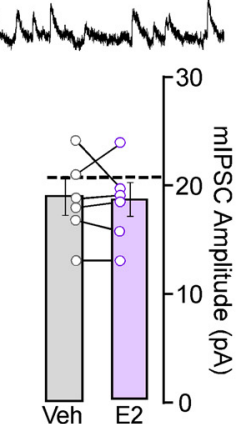

20 尔

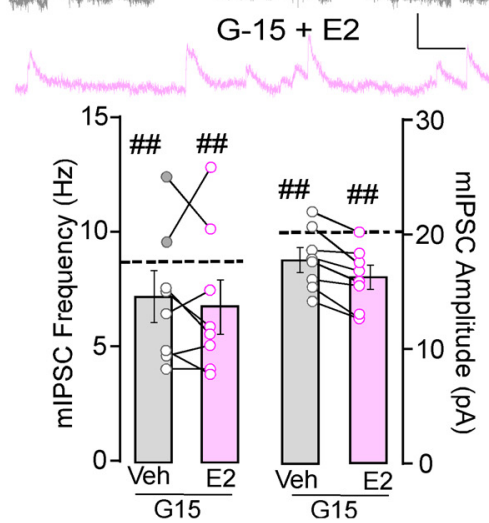

Figure 3. E2 potentiation of cocaine-primed reinstatement and E2 reductions in inhibitory synaptic transmission in PrL-PFC pyramidal neurons require activation of PrL-PFC ER $\beta$ and GPER1 but not $\operatorname{ER} \alpha$. $A$, Experimental timeline of experiments involving female rats implanted with bilateral guide cannulae targeting the PrL-PFC before cocaine self-administration, extinction, ovariectomy (OVX), and testing for the effects of intra-PrL antagonism of ER $\alpha$, ER $\beta$, and GPER1 on E2-potentiated cocaine-primed reinstatement. Intra-PrL effects of (B) the ER $\alpha$ antagonist MPP, $(\boldsymbol{C})$ the ER $\beta$ antagonist PHTPP and (D) the GPER1 antagonist G15 on E2-potentiated active lever pressing during a 2-h reinstatement test are shown compared with extinction. In each case, E2 in combination with cocaine elevated lever responding following intra-PrL vehicle microinfusions, while vehicle/saline, vehicle/cocaine, and E2/saline did not. PrL-PFC microinfusions of PHTPP or G15, but not MPP, blocked E2/cocaine-induced increases in responding relative to extinction. $\boldsymbol{E}$, Schematic depicting PrL-PFC cannula placements. $\boldsymbol{F}$, Timeline of ex vivo whole-cell 
2018), rats received bilateral E2 microinfusions before a cocaine injection (for design, see Fig. 2A). Similar to systemic E2, only the combination of E2 and cocaine significantly increased lever pressing compared with extinction responding (Fig. 2C). A twoway repeated measures ANOVA showed a main effect of reinstatement $\left(F_{(1,28)}=6.16, p=0.02\right)$, treatment $\left(F_{(3,28)}=3.44\right.$, $p=0.03)$, and a reinstatement $\times$ treatment interaction $\left(F_{(3,28)}=\right.$ $4.06, p=0.02$ ).

To better understand the cellular mechanisms underlying PrL E2-potentiated reinstatement, we conducted whole-cell voltage clamp recordings in PrL L5/6 pyramidal neurons (Fig. 2D-H) of ovariectomized females with no history of cocaine self-administration. Examination of excitatory signaling (AMPAR-mediated mEPSCs) showed that E2 bath application did not alter overall mEPSC amplitude or frequency (amplitude: $t_{(7)}=2.22, p=0.06$; frequency: $\left(t_{(7)}=-1.24, p=0.25 ; n=8 / N=4\right.$; Fig. $\left.2 E, F\right)$. By contrast, E2 significantly reduced the frequency but not amplitude of $\mathrm{GABA}_{\mathrm{A}} \mathrm{R}$-mediated mIPSC (frequency: $t_{(6)}=3.24, p=0.02$; amplitude $t_{(6)}=0.05, p=0.96 ; n=7, N=5$; Fig. $\left.2 G, H\right)$.

\section{Experiment \#3: Intra-PrL-PFC ER $\beta$ and GPER1 antagonism blocks E2-dependent reinstatement and suppression of $\mathrm{GABA}_{\mathrm{A}} \mathrm{R}$-mediated synaptic transmission}

We next examined the contributions of $\operatorname{ER} \alpha, \operatorname{ER} \beta$, and GPER1 receptor signaling to E2-mediated effects on cocaine-primed reinstatement and synaptic inhibition (for design, see Fig. $3 A$ ). Intra-PrL infusion of the $\mathrm{ER} \alpha$ antagonist, MPP, did not prevent E2-potentiated reinstatement (Fig. 3B). A two-way repeated measures ANOVA revealed a main effect of reinstatement $\left(F_{(1,33)}=8.76, p<0.01\right)$, treatment $\left(F_{(4,33)}=4.10, p<0.01\right)$, and a reinstatement $\times$ treatment interaction $\left(F_{(4,33)}=9.41, p<0.01\right)$. Post hoc testing revealed that while the combination of systemic E2 and cocaine significantly increased lever pressing relative to extinction, this occurred regardless of whether rats received a prior infusion of MPP or vehicle $(p<0.05)$. Comparison across reinstatement test conditions using one-way repeated measures ANOVA revealed that active lever responding during reinstatement was significantly greater in rats that received systemic E2 and cocaine following intra-PrL infusion of either vehicle or MPP compared with all other reinstatement conditions $\left(F_{(4,30)}=\right.$ $6.63, p<0.01 ; p<0.05$ for each comparison), however active lever pressing did not differ between these two groups.

In contrast to $\mathrm{ER} \alpha$, antagonism of $\mathrm{ER} \beta$ with a bilateral intraPrL infusion of PHTPP blocked E2-potentiated reinstatement (Fig. $3 C$ ). A two-way repeated measures ANOVA showed significant main effects of reinstatement $\left(F_{(1,35)}=6.06, p=0.02\right)$ and treatment $\left(F_{(4,35)}=4.06, p<0.01\right)$ and a significant reinstatement

recordings in PrL-PFC L5/6 pyramidal neurons examining mIPSC frequency and amplitude in aCSF, following a 10-min application of HBC, and 10-min application of HBC + E2 (top; data in $\boldsymbol{G}$ ) and (bottom) timeline of recordings performed following a 5-min application of $\mathrm{HBC}$, 10 min of $\mathrm{HBC}+$ antagonist, and 10 min of $\mathrm{HBC}+$ antagonist + E2 (data in $/-J$ ). Data were collected at time points denoted by arrows. $\mathbf{G}$, mIPSC frequency and amplitude (bottom) and representative traces (top). Dotted line denotes mean frequency and amplitude of mIPSCs collected in aCSF. Extended vehicle application did not alter frequency or amplitude of mIPSCs and subsequent E2 decreased mIPSC frequency but not amplitude $(\boldsymbol{G} ; * * p<0.05$ vs HBC). Effects of E2 in the presence of $(\boldsymbol{H})$ MPP, ( $\boldsymbol{l})$ PHTPP, and $(\boldsymbol{I}) \mathrm{G} 15$ on mIPSC. Panels include representative recordings (top) during application of $\mathrm{HBC}$, antagonist alone, and antagonist with E2 (scale: $20 \mathrm{pA} / 0.10 \mathrm{~s}$ ). Graphs (bottom) depict mIPSC frequency and amplitude with antagonist in combination with $\mathrm{HBC}$ vehicle or $\mathrm{E} 2$ with $\mathrm{HBC}$ baseline measures represented as dashed lines; $* p<0.05$ versus extinction; $* * p<0.05$ versus HBC + MPP; $\# \# p<0.05$ versus $\mathrm{HBC}$ baseline. $\times$ treatment interaction $\left(F_{(4,35)}=6.78, p<0.01\right)$. Post hoc tests show that, relative to extinction, lever responding was elevated in rats when receiving an infusion of vehicle before systemic E2 and cocaine, but not following infusion of PHTPP $(p<0.05)$. Comparison across test conditions revealed that active lever responding was also increased by intra-PrL vehicle E2/cocaine treatment compared with all other reinstatement conditions $\left(F_{(4,39)}=6.87, p<0.01 ; p<0.05\right.$ for each comparison $)$.

Using a similar approach to antagonize GPER1 signaling, intra-PrL G-15 delivery also prevented E2-potentiated reinstatement (Fig. 3D). A two-way repeated measures ANOVA showed no significant main effects of reinstatement $\left(F_{(1,30)}=0.60\right.$, $p=0.45)$ or treatment $\left(F_{(4,30)}=0.94, p=0.46\right)$ but revealed a significant reinstatement $\times$ treatment interaction $\left(F_{(4,30)}=2.81\right.$, $p=0.04)$. Post hoc testing revealed that active lever responding was increased relative to extinction only when rats received an intra-PrL vehicle infusion followed by systemic E2 and cocaine. Further, comparison across test conditions showed that active lever responding was significantly greater with intra-PrL vehicle E2/cocaine compared with all other reinstatement conditions ( $p<0.05$ for each comparison). Placements for all rats that received intra-PrL vehicle or antagonist infusions are depicted in Figure 3E.

To determine whether effects of E2 on inhibitory synaptic transmission were also attributable to a specific ER subtype; wholecell recordings were performed in the presence of receptor antagonists (for design, see Fig. 3F). Similar to our initial findings, mIPSC frequency was reduced following application of E2 (5.90 \pm $1.17 \mathrm{~Hz})$ compared with the initial aCSF baseline $(7.96 \pm 1.19 \mathrm{~Hz}$, $p<0.01)$ and the secondary HBC baseline $(7.96 \pm 1.19 \mathrm{~Hz}$, $\left.p<0.01 ; F_{(2,10)}=12.49 p=0.002 ; n=6 / N=5\right)$. No differences were observed in mIPSC frequency between aCSF and HBC baselines $(p=1.00)$. Further, no differences in mIPSC amplitude were observed between aCSF $(20.88 \pm 1.86 \mathrm{pA}), \mathrm{HBC}(18.49 \pm 1.46 \mathrm{pA})$, or HBC/E2 $\left(18.23 \pm 1.48 \mathrm{pA} ; F_{(2,10)}=3.23, p=0.08 ; n=6, N=5\right.$; Fig. $3 G$ ). Importantly, these data replicate initial observations with $\mathrm{E} 2$ and demonstrate that $\mathrm{HBC}$ under these conditions does not impact $\mathrm{GABA}_{\mathrm{A}} \mathrm{R}$ signaling.

Subsequent assessment of ER contribution showed that effects of E2 on mIPSC frequency were not prevented by MPP $\left(F_{(2,18)}=10.79, p<0.001 ; n=10 / N=5\right.$; Fig. $\left.3 H\right)$. Post hoc comparisons showed that application of MPP alone did not alter mIPSC frequency $(7.69 \pm 1.03 \mathrm{~Hz})$ compared with HBC (HBC: $8.15 \pm 0.99 \mathrm{~Hz}, p=0.43)$, however mIPSC frequency was significantly reduced following co-application of MPP and E2 $(6.21 \pm 0.81 \mathrm{~Hz})$ versus HBC baseline $(p<0.001)$ and HBC with MPP $(p=0.012)$. Similarly, MPP did not alter mIPSC amplitude $(20.53 \pm 1.36 \mathrm{pA})$ compared with $\mathrm{HBC}$ baseline (22.12 \pm $1.39 \mathrm{pA}, p=0.16)$, but co-application of MPP and E2 produced a significant reduction $\left(17.98 \pm 0.90 \mathrm{pA} ; F_{(2,18)}=12.90, p<0.01\right)$. In contrast, E2-dependent reductions in MIPSC frequency were no longer observed in the presence of $\operatorname{PHTPP}\left(F_{(2,14)}=1.81\right.$, $p=0.20)$, with no differences observed across HBC baseline (HBC:8.79 $\pm 0.66 \mathrm{~Hz}$ ) versus co-application of PHTPP (7.86 \pm $0.43 \mathrm{~Hz})$ or PHTPP/E2 $(7.56 \pm 0.70 \mathrm{~Hz})$. Effects were also not observed on mIPSC amplitude across any condition (HBC: $20.69 \pm 2.4 \mathrm{pA}$, PHTPP: $18.96 \pm 0.9 \mathrm{pA}$, PHTPP/E2: $17.56 \pm$ $0.89 \mathrm{pA} ; F_{(2,14)}=1.54, p=0.25 ; n=8 / N=5$; Fig. $\left.3 I\right)$.

Examination of GPER1 contributions showed an overall reduction in mIPSC frequency and amplitude across treatments (frequency: $F_{(2,14)}=4.65, p=0.03$; amplitude $\left(F_{(2,14)}=10.88\right.$, $p<0.01 ; n=8 / N=5$; Fig. $3 J)$. Post hoc analysis showed that similar to MPP, co-application of G15 and E2 resulted in significant 
reductions in frequency $(7.02 \pm 1.12 \mathrm{~Hz})$ and amplitude (16.42 $\pm 0.92 \mathrm{pA})$ compared with $\mathrm{HBC}$ baseline (frequency: $9.17 \pm 1.66 \mathrm{~Hz}, \quad p=0.04 ; \quad$ amplitude: $20.51 \pm 1.52 \mathrm{pA}, p<0.01)$. However, this significance was driven in part by G-15 application (frequency: $7.28 \pm$ $1.00 \mathrm{~Hz} ; \quad$ amplitude: $18.05 \pm 0.93 \mathrm{pA})$ following $\mathrm{HBC}$ baseline (frequency: $p=0.07$, amplitude: $p=0.04$ ), as no reduction in frequency or amplitude was observed with G-15 and E2 coapplication compared with G-15 alone (frequency: $p=0.94$; amplitude: $p=0.19$; Fig. 3J). Taken together, these findings suggest that, similar to behavioral effects, ER $\beta$ and GPER1 activation, but not $\mathrm{ER} \alpha$ activation, is necessary for E2-dependent reductions in GABAergic transmission in PrL L5/6 pyramidal neurons.

Experiment \#4: activation of PrL-PFC ER $\beta$, but not GPER1, reproduces effects of $\mathrm{E} 2$ on cocaine seeking reinstatement and $\mathrm{GABA}_{\mathrm{A}} \mathrm{R}$-mediated synaptic transmission

To determine the sufficiency of $\operatorname{ER} \beta$ for E2-potentiated reinstatement, DPN or vehicle was microinfused bilaterally into the PrL-PFC before a saline or cocaine injection and reinstatement testing (for design, see Fig. 4A). As was the case with E2, only DPN in combination with cocaine potentiated reinstatement (Fig. 4B). A two-way repeated measures ANOVA revealed a main effect of reinstatement $\left(F_{(1,42)}=3.94, p=0.05\right)$ but not treatment $\left(F_{(5,42)}=2.24, p=0.07\right)$, and a significant interaction between reinstatement and treatment $\left(F_{(5,42)}=2.38, p=0.05\right)$. Post hoc testing showed that vehicle, DPN, and cocaine combined with vehicle did not elevate cocaine seeking relative to extinction. However, lever pressing was increased by the combination of cocaine and infusion of the $100 \mathrm{pg}$, but not $10 \mathrm{pg}$, DPN dose $(p<0.05)$. Further, comparison across reinstatement conditions revealed that active lever pressing was increased by the combination of intraPrL 100 pg DPN/cocaine relative to the $100 \mathrm{pg} \mathrm{DPN} / \mathrm{saline}$ and vehicle/saline conditions $\left(F_{(5,47)}=3.15, p=0.02\right)$. Using a similar approach to assess GPER1 sufficiency, we found that intra-PrL G-1 did not potentiate reinstatement to a subthreshold cocaine injection (Fig. 4C). A two-way repeated measures ANOVA revealed no main effect of reinstatement $\left(F_{(1,36)}=2.48, p=0.12\right)$, treatment $\left(F_{(5,36)}=1.64, p=0.77\right)$, or interaction $\left(F_{(5,36)}=0.27\right.$, $p=0.93)$, indicating that PrL-PFC GPER1 activation is (\#\#p $<0.05$ vs HBC).

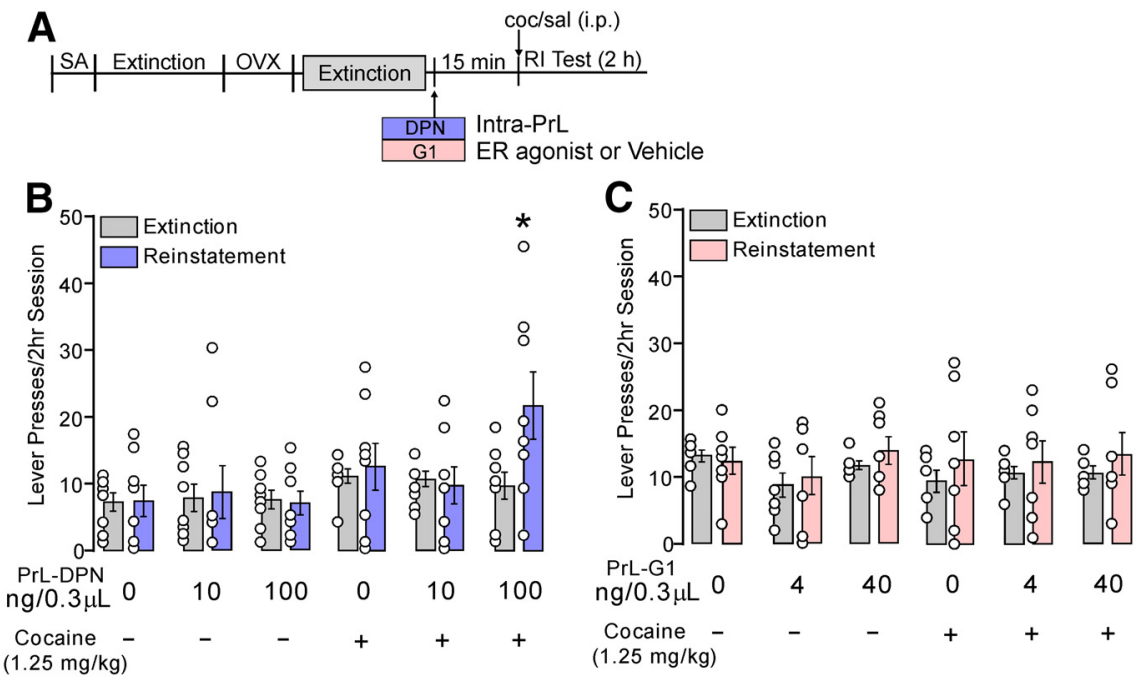

D
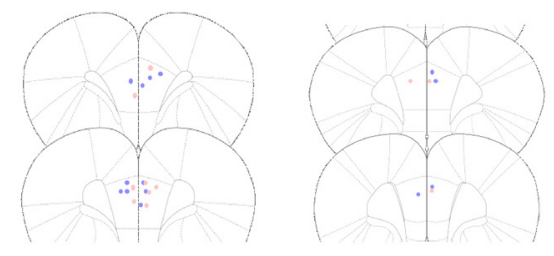

$\mathbf{F}$
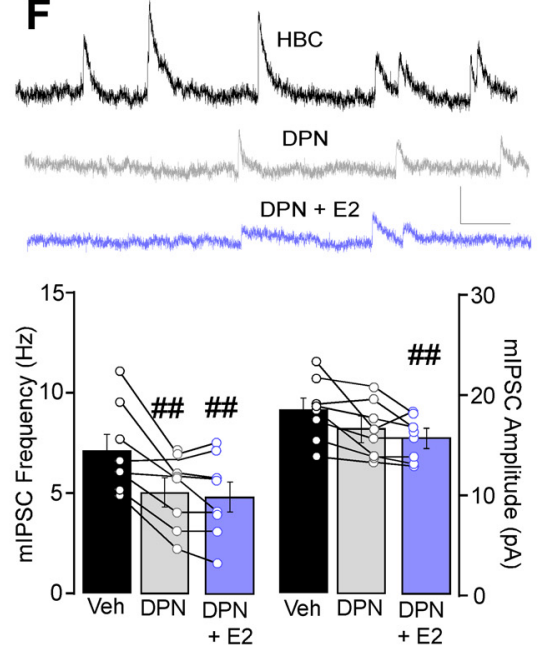

E
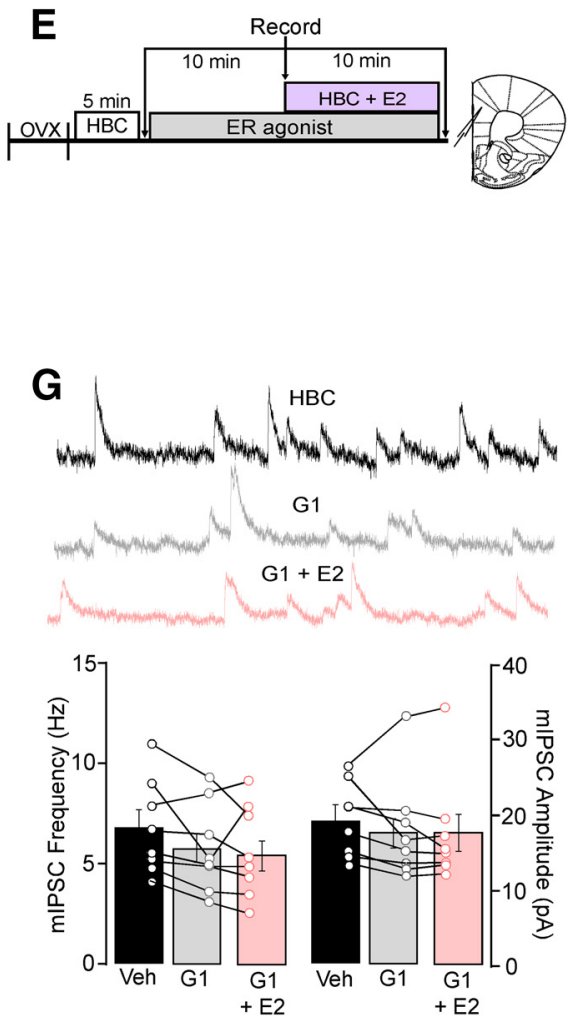

Figure 4. PrL-PFC ER $\beta$ but not GPER1 activation potentiates cocaine-primed reinstatement and decreases inhibitory synaptic transmission in PrL-PFC pyramidal neurons. $\boldsymbol{A}$, Timeline of experiments involving female rats implanted with bilateral guide cannulae targeting the PrL-PFC before cocaine self-administration, extinction, ovariectomy (OVX), and testing for the effects of intra-PrL ER $\beta$ agonist, DPN, or the GPER1 agonist, G1, to reproduce the effects of E2 on cocaine-primed reinstatement. Bilateral microinfusions of (B) DPN (100 but not $10 \mathrm{ng})$ but not (C) G1 potentiated cocaine-primed reinstatement $(* p<0.05$ vs extinction). D, Schematic depicting PrL-PFC cannula placements. $\boldsymbol{E}$, Timeline of ex vivo whole-cell recordings in PrL-PFC L5/6 pyramidal neurons examining effects of agonist-induced effects on mIPSC frequency and amplitude. Effects of $(\boldsymbol{F})$ DPN and $(\boldsymbol{G})$ G1 on mIPSCs. Panels include representative recordings (top) during application of vehicle alone, agonist alone, and co-application of agonist with E2 (scale: $20 \mathrm{pA} / 0.10 \mathrm{~s}$ ) and graphs depicting mIPSC frequency and amplitude under each condition

insufficient to potentiate reinstatement of cocaine seeking. Placements for infusions are depicted in Figure $4 D$.

Whole-cell recordings in cocaine naive rats showed that similar to the selective ability of $\operatorname{ER} \beta$ activation to increase cocaine seeking reinstatement, activation of $\operatorname{ER} \beta$, but not GPER1, 
Table 1. Final sample size $(n)$ and cocaine self-administration and extinction data for each experiment and experimental group

\begin{tabular}{|c|c|c|c|c|c|c|c|}
\hline \multirow[b]{2}{*}{ Experiment \# } & \multirow[b]{2}{*}{ Group } & \multirow[b]{2}{*}{$n$} & \multicolumn{2}{|c|}{$\begin{array}{l}\text { Self-administration } \\
\text { (responses/2-h session } \pm \text { SE) }\end{array}$} & \multicolumn{2}{|c|}{$\begin{array}{l}\text { Extinction (responses/2-h } \\
\text { session } \pm \text { SE) }\end{array}$} & \multirow{2}{*}{$\begin{array}{l}\text { Extinction duration } \\
\text { (\#sessions } \pm \mathrm{SE} \text { ) }\end{array}$} \\
\hline & & & Day 1 & Day 14 & First & Last & \\
\hline \multirow{3}{*}{1} & PPT (i.p.) & 5 & $119.8 \pm 13.9$ & $116.0 \pm 26.7$ & $97.7 \pm 28.9$ & $10.5 \pm 1.9$ & $20.8 \pm 6.6$ \\
\hline & DPN (i.p.) & 7 & $119.8 \pm 13.9$ & $123.8 \pm 28.8$ & $113.3 \pm 34.6$ & $11.6 \pm 1.9$ & $24.5 \pm 7.1$ \\
\hline & G-1 (i.p.) & 6 & $123.3 \pm 2.9$ & $113.8 \pm 10.3$ & $107.3 \pm 14.1$ & $11.0 \pm 2.1$ & $15.0 \pm 4.5$ \\
\hline \multirow{2}{*}{3} & PHTPP (intra-PrL) & 8 & $110.4 \pm 8.5$ & $107.1 \pm 5.5$ & $104.7 \pm 24.3$ & $12.0 \pm 2.0$ & $21.0 \pm 4.6$ \\
\hline & G-15 (intra-PrL) & 7 & $124.5 \pm 13.2$ & $108.0 \pm 11.2$ & $97.5 \pm 31.5$ & $11.9 \pm 1.9$ & $18.6 \pm 4.4$ \\
\hline \multirow[t]{2}{*}{4} & DPN (intra-PrL) & 8 & $129.8 \pm 9.2$ & $126.3 \pm 15.2$ & $111.0 \pm 28.9$ & $11.6 \pm 1.1$ & $15.6 \pm 4.4$ \\
\hline & G-1 (intra-PrL) & 7 & $125.3 \pm 2.8$ & $120.8 \pm 12.5$ & $129.0 \pm 9.8$ & $13.3 \pm 1.7$ & $18.1 \pm 4.5$ \\
\hline
\end{tabular}

sufficiently reduced $\mathrm{GABA}_{\mathrm{A}} \mathrm{R}$-IPSCs (for design, see Fig. $4 E$ ). Analogous to ex vivo effects of E2, bath application of DPN significantly reduced mIPSC frequency $(5.33 \pm 0.67 \mathrm{~Hz})$ compared with $\mathrm{HBC}$ baseline $(7.52 \pm 0.82 \mathrm{~Hz}, p<0.01)$. Subsequent coapplication of E2 further reduced frequency compared with baseline $(5.03 \pm 0.77 \mathrm{~Hz}, p<0.01)$, but not compared with DPN alone $\left(p=0.86 ; F_{(2,14)}=11.57, p<0.01 ; n=8\right.$; Fig. $\left.4 F\right)$. In contrast to previously observed effects of E2, DPN reduced mIPSC amplitude $(16.10 \pm 0.99 \mathrm{pA})$ compared with $\mathrm{HBC}$ baseline $(18.24 \pm 1.07 \mathrm{pA}, p=0.03)$. mIPSC amplitude in the presence of DPN and E2 $(15.39 \pm 0.75)$ was also lower than baseline $(p=0.004)$ but did not differ from DPN alone $\left(p=0.59 ; F_{(2,14)}=\right.$ $8.52, p<0.01)$. Conversely, activation of GPER1 did not suppress mIPSCs as no significant differences in mIPSC frequency $\left(F_{(2,14)}=3.70\right)$ or mIPSC amplitude $\left(F_{(2,14)}=1.02\right)$ were observed comparing baseline, G1 alone, and G1 + E2 (Fig. 4G). As a role for $\mathrm{ER} \alpha$ in drug-seeking reinstatement was not identified in either systemic or intra-PrL experiments nor was $\mathrm{ER} \alpha$ necessary for the reductions in mIPSC frequency following E2 application, $\mathrm{ER} \alpha$ tests of sufficiency from these studies were not performed.

\section{Discussion}

Consistent with findings that cocaine craving is greater in women (Robbins et al., 1999; Elman et al., 2001; Kennedy et al., 2013), we and others have found that female rats are more susceptible to cocaine-primed reinstatement than males (Lynch and Carroll, 2000; Kerstetter et al., 2008; Doncheck et al., 2020). Moreover, similar to what is observed with drug seeking in response to stressors and cocaine-associated cues (Feltenstein et al., 2011; Doncheck et al., 2020), we have found that low-dose cocaine-primed reinstatement is most pronounced in proestrus when circulating levels of E2 are elevated (Doncheck et al., 2018). Notably, this finding is in contrast to some reports that sensitivity to cocaine-primed reinstatement is increased during estrus (Kippin et al., 2005; Feltenstein and See, 2007; Nicolas et al., 2019). Based on these observations, we hypothesize that elevated E2 contributes to sex-dependent and reproductive cycledependent differences in relapse susceptibility. In support of this hypothesis, our present findings demonstrate that mimicking proestrus-level E2 concentrations potentiates cocaine-primed reinstatement in ovariectomized female rats through actions in the PrL-PFC. Moreover, we find that E2-dependent increases in the reinstatement of extinguished cocaine seeking requires the coordinated activation of ER $\beta$ and GPER1 in the PrL-PFC but does not involve ER $\alpha$. Finally, we demonstrate that E2-dependent effects are likely attributable to reductions in GABA release and signaling via $\mathrm{GABA}_{\mathrm{A}}$ Rs. Overall, our data indicate that the E2-induced activation of $\operatorname{ER} \beta$ and GPER1 contribute to the influence of sex and reproductive phase on relapse susceptibility by attenuating the synaptic inhibition of PrL-PFC outputs.

Elevated estrogens during the menstrual cycle, as well as E2 administration to perimenopausal or postmenopausal women, is associated with task- dependent changes in PFC reactivity and alterations in PFC-dependent cognition and emotional processing (Joffe et al., 2006; Amin et al., 2006; Dreher et al., 2007; Zeidan et al., 2011; Girard et al., 2017). A similar E2-dependent regulation has also been observed in the PrL-PFC in female rats (Sinopoli et al., 2006). E2 regulation of PFC activity may have implications for SUDs, as PFC activity under conditions that promote drug craving is increased in women compared with men (Kilts et al., 2004) and E2-potentiation of cocaine seeking in female rodents corresponds to heightened PrL c-fos reactivity (Zhou et al., 2014).

$\mathrm{ER} \alpha, \mathrm{ER} \beta$, and GPER 1 are all expressed in the rat PrL-PFC and are primarily localized to axons/terminals, although some postsynaptic and astrocytic expression has been reported (Kritzer and Creutz, 2008; Almey et al., 2014; Crimins et al., 2017). These receptors are largely membrane-associated in the PFC (Almey et al., 2014) and participate in the non-canonical rapid signaling through which E2 influences synaptic physiology (Woolley, 2007). It has been reported that $\mathrm{ER} \beta$ is predominantly expressed by fast-spiking PV + interneurons in the neocortex (Blurton-Jones et al., 2004). Consistent with this expression profile, we find that E2 attenuates pyramidal neuron mIPSC frequency but not amplitude and that this effect is $\operatorname{ER} \beta$-dependent. Thus, we hypothesize that $\operatorname{ER} \beta$ activation attenuates GABA release from PV + interneurons in the PrL-PFC, thereby reducing inhibitory regulation of pyramidal neuron output pathways that mediate drug seeking. Accordingly, the effects of E2 on mIPSC frequency were reproduced by the $\operatorname{ER} \beta$ agonist, DPN, and prevented by the ER $\beta$ antagonist, PHTPP - effects that paralleled those on the reinstatement of cocaine seeking. The mechanism through which $\mathrm{ER} \beta$ attenuates GABA release is unclear. Localization to $\mathrm{PV}+$ interneurons would imply direct regulation of firing patterns and/or release. However, we cannot rule out the possibility of indirect regulation of GABA release (e.g., via endocannabinoid mobilization) as we have previously shown that glucocorticoid-potentiated cocaine seeking also aligns with suppression of mIPSC frequency in the PrL-PFC via increased synthesis of 2-AG and retrograde activation of $\mathrm{CB} 1$ receptors (McReynolds et al., 2018; Hill et al., 2011; Doncheck et al., 2020). Similar to the influence of corticosterone, we found that the effects of systemic E2 on cocaine seeking are attenuated by PrL 
microinfusions of the CB1 receptor inverse agonist, AM251 (Doncheck et al., 2018). Future work will determine whether the mechanism underlying ER $\beta$ effects on inhibitory transmission overlaps with that of glucocorticoids or whether it is complementary, thereby allowing for additive effects.

Behavioral and electrophysiological data in the current study demonstrate that ER $\beta$ in the PrL-PFC is necessary for E2-mediated effects and is sufficient to potentiate reinstatement of cocaine seeking and suppress GABAergic transmission. However, the contribution of GPER1 in these effects appears more complex. As was the case with cocaine-seeking reinstatement, antagonism of GPER1 prevented E2-dependent reductions in MIPSC frequency. However, agonist-induced activation of GPER1 failed to reproduce effects of E2 on behavior and synaptic transmission, suggesting that GPER1 may work in concert with $\operatorname{ER} \beta$ to play a permissive role in E2 effects on inhibitory synaptic transmission. In support, GPER1 and ER $\beta$ have similar expression profiles in the PFC; however, the degree to which they colocalize and whether and how they interact is not known. Notably, there is some evidence that GPER1 collaborates with other ERs to regulate cellular function and behavior (Hadjimarkou and Vasudevan, 2018). However, most of these interactions appear to involve $\operatorname{ER} \alpha$, which has been found to be phosphorylated in the hippocampus following GPER1 activation in male rats (Hart et al., 2014). Unlike previous findings in the hippocampus (Huang and Woolley, 2012), we found no evidence of $\operatorname{ER} \alpha$ mediation of $\mathrm{E} 2$ effects in the PrL-PFC on either synaptic transmission or behavior. Future studies aimed at understanding the cellular mechanisms through which GPER1 contributes to E2-mediated influences on PrL-PFC physiology and behavior will have important implications.

Although we did not observe an overall significant effect of E2 on excitatory synaptic transmission, it is noteworthy that a subset of pyramidal neurons displayed increases in mEPSC frequency. Thus, E2 likely also promotes changes in excitatory drive in a subpopulation of PrL-PFC neurons. In agreement, ER $\beta$-dependent E2-induced increases in MEPSC frequency have been reported in hippocampal CA1 pyramidal neurons with subpopulation effects (Oberlander and Woolley, 2016). Additionally, while we did not examine the effects of E2 on intrinsic excitability, it has also been reported that E2 slice application enhances excitability in the infralimbic medial PFC (Yousuf et al., 2019). It will be important to more selectively characterize the influence of E2 on intrinsic membrane physiology and excitatory synaptic signaling to fully understand how E2 impacts PrL-PFC function.

There are several limitations to this study that should be acknowledged. First, although rats were gonadally intact throughout SA and extinction, reinstatement testing was conducted following ovariectomy to permit temporally precise production of proestrus E2 levels; isolation of ER mechanisms and ovariectomy has been reported to alter ER expression (Ehret and Buckenmaier, 1994; Rose'Meyer et al., 2003). Moreover, our experiments do not address alterations in progesterone, which has been found to suppress cocaine seeking in rats (Anker et al., 2007; Feltenstein et al., 2009). Second, although there is close alignment between the findings from our behavior and electrophysiology studies, synaptic physiology was assessed only in rats with no history of cocaine SA. Thus, these experiments do not account for potential cocaine-induced neuroadaptations in ERs. Third, testing was only conducted in female rats. The estrogensynthesizing enzyme, aromatase (CYP19A1), ER $\beta$, and GPER1 are all expressed in the male PFC (Hutson et al., 2019) and, therefore, it is possible that E2 can regulate drug seeking via similar PrL-PFC mechanisms in male rats. Fourth, while our findings implicate $\mathrm{ER} \beta$ and GPER1 signaling and, likely, regulation of inhibitory synaptic transmission in the PrL-PFC in E2-potentiated cocaine seeking, they do not address the heterogeneous population of pyramidal neurons in the region. Future experiments isolating neuronal subpopulations based on efferent targets and/or molecular phenotypes are needed. Finally, while our results implicate signaling in the PrL-PFC in E2-potentiated cocaine seeking, they do not rule out contributions of other brain regions to systemic E2 and sex-/phase-dependent effects. Indeed, E2 exerts effects in other brain regions involved in drug seeking (Peterson et al., 2016; Vandegrift et al., 2017; Song et al., 2019).

In conclusion, these findings provide a better mechanistic understanding of how estrogens regulate relapse to cocaine use and may contribute to sex-dependent and reproductive phasedependent differences in drug seeking. Moreover, as hormonal regulation of the PrL-PFC likely influences numerous processes related to goal-directed/motivated behavior, cognition, behavioral flexibility and attention, these results may provide broader insight into how estrogen-mediated reproductive brain states guide behavior.

\section{References}

Almey A, Cannell E, Bertram K, Filardo E, Milner TA, Brake WG (2014) Medial prefrontal cortical estradiol rapidly alters memory system bias in female rats: ultrastructural analysis reveals membrane-associated estrogen receptors as potential mediators. Endocrinology 155:4422-4432.

Amin Z, Epperson CN, Constable RT, Canli T (2006) Effects of estrogen variation on neural correlates of emotional response inhibition. Neuroimage 32:457-464.

Anderson EM, Gomez D, Caccamise A, McPhail D, Hearing M (2019) Chronic unpredictable stress promotes cell-specific plasticity in prefrontal cortex D1 and D2 pyramidal neurons. Neurobiol Stress 10:100152.

Anker JJ, Larson EB, Gliddon LA, Carroll ME (2007) Effects of progesterone on the reinstatement of cocaine-seeking behavior in female rats. Exp Clin Psychopharmacol 15:472-480.

Becker JB, Chartoff E (2019) Sex differences in neural mechanisms mediating reward and addiction. Neuropsychopharmacology 44:166-183.

Blurton-Jones M, Kuan PN, Tuszynski MH (2004) Anatomical evidence for transsynaptic influences of estrogen on brain-derived neurotrophic factor expression. J Comp Neurol 468:347-360.

Bonson KR, Grant SJ, Contoreggi CS, Links JM, Metcalfe J, Weyl HL, Kurian V, Ernst M London ED (2002) Neural systems and cue-induced cocaine craving. Neuropsychopharmacology 26:376-386.

Boulware MI, Heisler JD, Frick KM (2013) The memory-enhancing effects of hippocampal estrogen receptor activation involve metabotropic glutamate receptor signaling. J Neurosci 33:15184-15194.

Capriles N, Rodaros D, Sorge RE, Stewart J (2003) A role for the prefrontal cortex in stress- and cocaine-induced reinstatement of cocaine seeking in rats. Psychopharmacology (Berl) 168:66-74.

Clemens AM, Lenschow C, Beed P, Li L, Sammons R, Naumann RK, Wang H, Schmitz D, Brecht M (2019) Estrus-cycle regulation of cortical inhibition. Curr Biol 29:605-615.e6.

Crimins JL, Wang AC-J, Yuk F, Puri R, Janssen WGM, Hara Y, Rapp PR, Morrison JH (2017) Diverse synaptic distributions of G protein-coupled estrogen receptor 1 in monkey prefrontal cortex with aging and menopause. Cereb Cortex 27:2022-2033.

Domínguez-Ordóñez R, García-Juárez M, Lima-Hernández FJ, GómoraArrati P, Blaustein JD, Etgen AM, González-Flores O (2016) Estrogen receptor $\alpha$ and $\beta$ are involved in the activation of lordosis behavior in estradiol-primed rats. Horm Behav 86:1-7.

Doncheck EM, Urbanik LA, DeBaker MC, Barron LM, Liddiard GT, Tuscher JJ, Frick KM, Hillard CJ, Mantsch JR (2018) $17 \beta$-Estradiol potentiates the reinstatement of cocaine seeking in female rats: role of the prelimbic prefrontal cortex and cannabinoid type-1 receptors. Neuropsychopharmacology 43:781-790. 
Doncheck EM, Liddiard GT, Konrath CD (2020) Sex, stress, and prefrontal cortex: influence of biological sex on stress-promoted cocaine seeking. Neuropsychopharmacology 45:1974-1985.

Dreher JC, Schmidt PJ, Kohn P, Furman D, Rubinow D, Berman KF (2007) Menstrual cycle phase modulates reward-related neural function in women. Proc Natl Acad Sci USA 104:2465-2470.

Ehret G, Buckenmaier J (1994) Estrogen-receptor occurrence in the female mouse brain: effects of maternal experience, ovariectomy, estrogen and anosmia. J Physiol 88:315-329.

Elman I, Karlsgodt KH, Gastfriend DR (2001) Gender differences in cocaine craving among non-treatment-seeking individuals with cocaine dependence. Am J Drug Alcohol Abuse 27:193-202.

Feltenstein MW, See RE (2007) Plasma progesterone levels and cocaine-seeking in freely cycling female rats across the estrous cycle. Drug Alcohol Depend 89:183-189.

Feltenstein MW, Byrd EA, Henderson AR, See RE (2009) Attenuation of cocaine-seeking by progesterone treatment in female rats. Psychoneuroendocrinology 34:343-352.

Feltenstein MW, Henderson AR, See RE (2011) Enhancement of cueinduced reinstatement of cocaine-seeking in rats by yohimbine: sex differences and the role of the estrous cycle. Psychopharmacology (Berl) 216:53-62.

Gallop RJ, Crits-Christoph P, Ten Have TR, Barber JP, Frank A, Griffin ML, Thase ME (2007) Differential transitions between cocaine use and abstinence for men and women. J Consult Clin Psychol 75:95-103.

Girard R, Météreau E, Thomas J, Pugeat M, Qu C, Dreher JC (2017) Hormone therapy at early post-menopause increases cognitive controlrelated prefrontal activity. Sci Rep 7:44917.

Griffin ML, Weiss RD, Mirin SM, Lange U (1989) A comparison of male and female cocaine abusers. Arch Gen Psychiatry 46:122-126.

$\mathrm{Gu}$ Q, Moss RL (1996) 17beta-estradiol potentiates kainate-induced currents via activation of the cAMP cascade. J Neurosci 16:3620-3629.

Haas AL, Peters RH (2000) Development of substance abuse problems among drug-involved offenders. Evidence for the telescoping effect. J Subst Abuse 12:241-253.

Hadjimarkou MM, Vasudevan N (2018) GPER1/GPR30 in the brain: crosstalk with classical estrogen receptors and implications for behavior. J Steroid Biochem Mol Biol 176:57-64.

Hart D, Nilges M, Pollard K, Lynn T, Patsos O, Shiel C, Clark SM, Vasudevan N (2014) Activation of the G-protein coupled receptor 30 (GPR30) has different effects on anxiety in male and female mice. Steroids 81:49-56.

Hearing M, Kotecki L, Marron Fernandez de Velasco E, Fajardo-Serrano A, Chung HJ, Luján R, Wickman K (2013) Repeated cocaine weakens GABA(B)-Girk signaling in layer 5/6 pyramidal neurons in the prelimbic cortex. Neuron 80:159-170.

Hill MN, McLaughlin RJ, Pan B, Fitzgerald ML, Roberts CJ, Lee TT, Karatsoreos IN, Mackie K, Viau V, Pickel VM, McEwen BS, Liu QS, Gorzalka BB, Hillard CJ (2011) Recruitment of prefrontal cortical endocannabinoid signaling by glucocorticoids contributes to termination of the stress response. J Neurosci 31:10506-10515.

Huang GZ, Woolley CS (2012) Estradiol acutely suppresses inhibition in the hippocampus through a sex-specific endocannabinoid and mGluR-dependent mechanism. Neuron 74:801-808.

Hutson DD, Gurrala R, Ogola BO, Zimmerman MA, Mostany R, Satou R, Lindsey SH (2019) Estrogen receptor profiles across tissues from male and female Rattus norvegicus. Biol Sex Differ 10:4

Joffe H, Hall JE, Gruber S, Sarmiento IA, Cohen LS, Yurgelun-Todd D, Martin KA (2006) Estrogen therapy selectively enhances prefrontal cognitive processes: a randomized, double-blind, placebo-controlled study with functional magnetic resonance imaging in perimenopausal and recently postmenopausal women. Menopause 13:411-422.

Kastenberger I, Lutsch C, Schwarzer C (2012) Activation of the G-proteincoupled receptor GPR30 induces anxiogenic effects in mice, similar to oestradiol. Psychopharmacology (Berl) 221:527-535.

Kennedy AP, Epstein DH, Phillips KA, Preston KL (2013) Sex differences in cocaine/heroin users: drug-use triggers and craving in daily life. Drug Alcohol Depend 132:29-37.

Kerstetter KA, Aguilar VR, Parrish AB, Kippin TE (2008) Protracted timedependent increases in cocaine-seeking behavior during cocaine withdrawal in female relative to male rats. Psychopharmacology 198:63-75.
Kilts CD, Gross RE, Ely TD, Drexler KP (2004) The neural correlates of cueinduced craving in cocaine-dependent women. Am J Psychiatry 161:233241.

Kim J, Szinte JS, Boulware MI, Frick KM (2016) $17 \beta$-estradiol and agonism of G-protein-coupled estrogen receptor enhance hippocampal memory via different cell-signaling mechanisms. J Neurosci 36:3309-3321.

Kippin TE, Fuchs RA, Mehta RH, Case JM, Parker MP, Bimonte-Nelson HA, See RE (2005) Potentiation of cocaine-primed reinstatement of drug seeking in female rats during estrus. Psychopharmacology (Berl) 182:245-252.

Kosten TA, Gawin FH, Kosten TR, Rounsaville BJ (1993) Gender differences in cocaine use and treatment response. J Subst Abuse Treat 10:63-66.

Krentzel AA, Barrett LR, Meitzen J (2019) Estradiol rapidly modulates excitatory synapse properties in a sex- and region-specific manner in rat nucleus accumbens core and caudate-putamen. J Neurophysiol 122:12131225.

Kritzer MF, Creutz LM (2008) Region and sex differences in constituent dopamine neurons and immunoreactivity for intracellular estrogen and androgen receptors in mesocortical projections in rats. J Neurosci 28:9525-9535.

Larson EB, Carroll ME (2007) Estrogen receptor beta, but not alpha, mediates estrogen's effect on cocaine-induced reinstatement of extinguished cocaine-seeking behavior in ovariectomized female rats. Neuropsychopharmacol 32:1334-1345.

Lund TD, Rovis T, Chung WC, Handa RJ (2005) Novel actions of estrogen receptor-beta on anxiety-related behaviors. Endocrinology 146:797-807.

Lynch WJ, Carroll ME (2000) Reinstatement of cocaine self-administration in rats: sex differences. Psychopharmacology (Berl) 148:196-200.

McHenry JA, Otis JM, Rossi MA, Robinson JE, Kosyk O, Miller NW, McElligott ZA, Budygin EA, Rubinow DR, Stuber GD (2017) Hormonal gain control of a medial preoptic area social reward circuit. Nat Neurosci 20:449-458.

Maas LC, Lukas SE, Kaufman MJ, Weiss RD, Daniels SL, Rogers VW, Kukes TJ, Renshaw PF (1998) Functional magnetic resonance imaging of human brain activation during cue-induced cocaine craving. Am J Psychiatry 155:124-126.

McFarland K, Lapish CC, Kalivas PW (2003) Prefrontal glutamate release into the core of the nucleus accumbens mediates cocaine-induced reinstatement of drug-seeking behavior. J Neurosci 23:3531-3537.

McReynolds JR, Doncheck EM, Li Y, Vranjkovic O, Graf EN, Ogasawara D, Cravatt BF, Baker DA, Liu QS, Hillard CJ, Mantsch JR (2018) Stress promotes drug seeking through glucocorticoid-dependent endocannabinoid mobilization in the prelimbic cortex. Biol Psychiatry 84:85-94.

Mukherjee J, Cardarelli RA, Cantaut-Belarif Y, Deeb TZ, Srivastava DP, Tyagarajan SK, Pangalos MN, Triller A, Maguire J, Brandon NJ, Moss SJ (2017) Estradiol modulates the efficacy of synaptic inhibition by decreasing the dwell time of GABAA receptors at inhibitory synapses. Proc Natl Acad Sci USA 114:11763-11768.

Nicolas C, Russell TI, Pierce AF, Maldera S, Holley A, You Z-B, McCarthy MM, Shaham Y, Ikemoto S (2019) Incubation of cocaine craving after intermittent-access self-administration: sex differences and estrous cycle. Biol Psychiatry 85:915-924.

Oberlander JG, Woolley CS (2016) $17 \beta$-estradiol acutely potentiates glutamatergic synaptic transmission in the hippocampus through distinct mechanisms in males and females. J Neurosci 36:2677-2690.

Park WK, Bari AA, Jey AR, Anderson SM, Spealman RD, Rowlett JK, Pierce RC (2002) Cocaine administered into the medial prefrontal cortex reinstates cocaine-seeking behavior by increasing AMPA receptor-mediated glutamate transmission in the nucleus accumbens. J Neurosci 22:29162925.

Pereira LM, Bastos CP, de Souza JM, Ribeiro FM, Pereira GS (2014) Estradiol enhances object recognition memory in Swiss female mice by activating hippocampal estrogen receptor $\alpha$. Neurobiol Learn Mem 114:1-9.

Peterson BM, Martinez LA, Meisel RL, Mermelstein PG (2016) Estradiol impacts the endocannabinoid system in female rats to influence behavioral and structural responses to cocaine. Neuropharmacology 110:118-124.

Pytel M, Mercik K, Mozrzymas JW (2006) Interaction between cyclodextrin and neuronal membrane results in modulation of $\mathrm{GABA}(\mathrm{A})$ receptor conformational transitions. Br J Pharmacol 148:413-422.

Robbins SJ, Ehrman RN, Childress AR, O’Brien CP (1999) Comparing levels of cocaine cue reactivity in male and female outpatients. Drug Alcohol Depend 53:223-230. 
Rose'Meyer RB, Mellick AS, Garnham BG, Harrison GJ, Massa HM, Griffiths LR (2003) The measurement of adenosine and estrogen receptor expression in rat brains following ovariectomy using quantitative PCR analysis. Brain Res Brain Res Protoc 11:9-18.

Sinopoli KJ, Floresco SB, Galea LA (2006) Systemic and local administration of estradiol into the prefrontal cortex or hippocampus differentially alters working memory. Neurobiol Learn Mem 86:293-304.

Smejkalova T, Woolley CS (2010) Estradiol acutely potentiates hippocampal excitatory synaptic transmission through a presynaptic mechanism. J Neurosci 30:16137-16148.

Sofuoglu M, Dudish-Poulsen S, Nelson D, Pentel PR, Hatsukami DK (1999) Sex and menstrual cycle differences in the subjective effects from smoked cocaine in humans. Exp Clin Psychopharmacol 7:274-283.

Song Z, Yang H, Peckham EM, Becker JB (2019) Estradiol-induced potentiation of dopamine release in dorsal striatum following amphetamine administration requires estradiol receptors and mGlu5. eNeuro 6: ENEURO.0446-18.2019.

Stefanik MT, Moussawi K, Kupchik YM, Smith KC, Miller RL, Huff ML, Deisseroth K, Kalivas PW, LaLumiere RT (2013) Optogenetic inhibition of cocaine seeking in rats. Addict Biol 18:50-53.

Substance Abuse and Mental Health Services Administration (2020) 2019 National Survey on Drug Use and Health. Rockville: Center for Behavioral Health Statistics and Quality, Substance Abuse and Mental Health Services Administration. Available at https://www.samhsa.gov/data/.

Sun K, Wang F, Ma L, Ren X, Zhang C, Rong W, Sun T (2020) Genetic knockout of the $\mathrm{G}$ protein-coupled estrogen receptor 1 facilitates the acquisition of morphine-induced conditioned place preference and aversion in mice. Biochem Biophys Res Commun 525:1061-1067.

Terner JM, de Wit H (2006) Menstrual cycle phase and responses to drugs of abuse in humans. Drug Alcohol Depend 84:1-13.

Vandegrift BJ, You C, Satta R, Brodie MS, Lasek AW (2017) Estradiol increases the sensitivity of ventral tegmental area dopamine neurons to dopamine and ethanol. PLoS One 12:e0187698.

Wang W, Kantorovich S, Babayan AH, Hou B, Gall CM, Lynch G (2016) Estrogen's effects on excitatory synaptic transmission entail integrin and $\operatorname{trkB}$ transactivation and depend upon $\beta 1$-integrin function. Neuropsychopharmacol 41:2723-2732.

Wong M, Moss RL (1992) Long-term and short-term electrophysiological effects of estrogen on the synaptic properties of hippocampal CA1 neurons. J Neurosci 12:3217-3225

Woolley CS (2007) Acute effects of estrogen on neuronal physiology. Annu Rev Pharmacol Toxicol 47:657-680.

Yousuf H, Smies CW, Hafenbreidel M, Tuscher JJ, Fortress AM, Frick KM, Mueller D (2019) Infralimbic estradiol enhances neuronal excitability and facilitates extinction of cocaine seeking in female rats via a BDNF/ TrkB mechanism. Front Behav Neurosci 13:168.

Zeidan MA, Igoe SA, Linnman C, Vitalo A, Levine JB, Klibanski A, Goldstein JM, Milad MR (2011) Estradiol modulates medial prefrontal cortex and amygdala activity during fear extinction in women and female rats. Biol Psychiatry 70:920-927.

Zhou L, Pruitt C, Shin CB, Garcia AD, Zavala AR, See RE (2014) Fos expression induced by cocaine-conditioned cues in male and female rats. Brain Struct Funct 219:1831-1840. 